\title{
REVIEWS
}

\section{Structure formation and evolution in semiconductor films for perovskite and organic photovoltaics}

\author{
Andrew J. Pearson ${ }^{\text {a) }}$ \\ Cavendish Laboratory, University of Cambridge, Cambridge CB3 OHE, U.K.
}

(Received 20 December 2016; accepted 21 February 2017)

\begin{abstract}
The research and development of novel photovoltaic technologies is going through a golden era, thanks to the demonstration of remarkable efficiencies across a broad range of semiconductor classes and device architectures. In parallel with these developments, the opportunities for characterizing the structure of a semiconductor film in situ of a processing step have also increased, to the extent that in situ and in operando experiments are becoming readily accessible to researchers. These combined advances represent the subject matter of this article, wherein studies that improve our understanding of structure formation and evolution in perovskite and organic semiconductor films for innovative solar cells are reviewed. Although focus is placed on the dynamics of semiconductor film formation, the review also highlights recent research on environmental testing, a key component in the development of materials with high intrinsic stability.
\end{abstract}

\section{INTRODUCTION}

Photovoltaics (PVs) have evolved over the past several decades to become a truly global renewable technology. ${ }^{1-3}$ Since 1995 the annual growth rate of deployed solar power capacity has averaged $43 \%$ and as of writing over $230 \mathrm{GWp}$ of installed capacity exists worldwide. ${ }^{4,5}$ To build upon this trend, and benefit further from largescale PV deployment, continued investment, research and development is required such that newer materials and manufacturing processes can be commercialized. ${ }^{6}$ As with many technologies, the goal for PV is to realize systems that offer high performance at intrinsically low cost. Importantly, the solar cells and solar modules of the future will be developed not only for traditional forms of power generation, such as farms and rooftop installations, but also for a wider range of innovative applications than is currently realized. Specifically, examples where direct PV module incorporation is desired include building integrated $\mathrm{PV}$, portable $\mathrm{PV}$, and $\mathrm{PV}$ interfaced with flexible electronics. Recent breakthroughs have brought these opportunities much closer to reality, and as a consequence contemporary PVs R\&D describes a vibrant and highly dynamic activity.

The purpose of this review is to highlight recent advances in one area of PV research, namely, the knowledge gained through in situ measurements that

\footnotetext{
Contributing Editor: Dean DeLongchamp

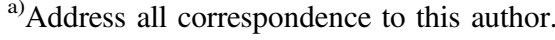

e-mail: ap824@cam.ac.uk

DOI: $10.1557 /$ jmr.2017.87
}

relate the optoelectronic properties of a device to the composition and crystal structure of the semiconductor layer. ${ }^{7}$ Structure-property relationships often provide the basis for realizing improvements in technology performance as they allow researchers to relate physical processes to key lengthscales within a material or to construct a framework for the targeted design of improved materials and processes. These results are discussed in the context of developments in equipment capability and measurement resolution, as these have provided further opportunities for advancement by identifying phenomena that were previously unknown or poorly understood. Emerging PVs based on two topical semiconductor classes-perovskites and organics-will form the main discussion sections as they have both seen significant improvements in efficiency over the past decade, ${ }^{8,9}$ in addition to offering rapid repayment times for cost and embedded energy. ${ }^{10,11}$ Indeed, for perovskite PVs at the laboratory stage of development, initial power conversion efficiencies (PCEs) that are comparable to multicrystalline $\mathrm{Si}, \mathrm{CdTe}$, and CIGS have now been reached. ${ }^{12}$ As with any promising emerging technology, however, inevitable hurdles exist on the path toward commercialization and widespread adoption. Discussing these challenges, as well as the ability of in situ and in operando measurements to overcome them, will form the final part of this review.

For readers who are unfamiliar with scattering techniques, Fig. 1 illustrates schematically the general setups for X-ray diffraction (XRD) and X-ray scattering experiments as these will be referred to repeatedly throughout this article. ${ }^{13,14}$ In an XRD measurement [part (a)], the 


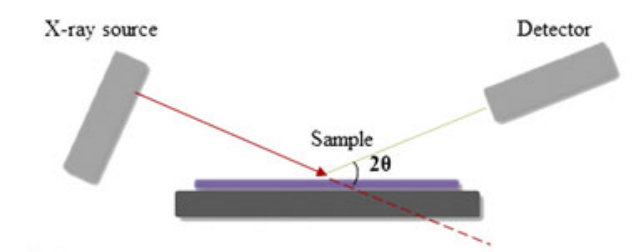

(a)

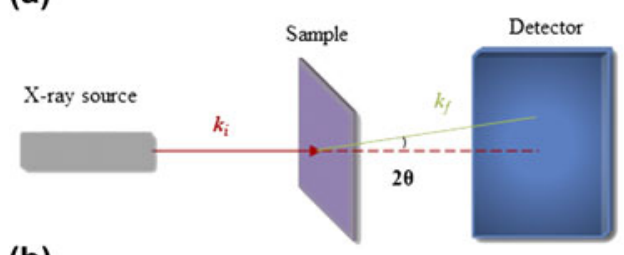

(b)

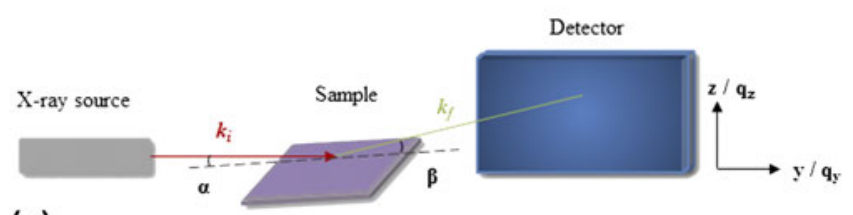

(c)

FIG. 1. Overview of the primary sample characterization methods discussed in this work. (a) XRD, (b) X-ray scattering, (c) grazingincidence $\mathrm{X}$-ray scattering.

$\mathrm{X}$-ray source and detector can each be rotated around a fixed sample by an angle $\theta$, the so-called BraggBrentano configuration. The angle between the source and detector is thus $2 \theta$, and X-rays diffracted by the sample are measured as a function of this parameter. In part (b), the generic setup for a transmission X-ray scattering measurement is presented. Here, $\mathrm{X}$-rays with initial wavevector $k_{\mathrm{i}}$ pass through the sample and elastically scattered X-rays (with wavevector $k_{\mathrm{f}}$ ) are measured using a two-dimensional detector. Convention dictates that a small angle X-ray scattering (SAXS) experiment measures scattering at $2 \theta$ values below $\sim 5^{\circ}$ and wide-angle X-ray scattering (WAXS) experiments measure above this. If the sample is instead positioned at a shallow angle $\alpha$ to the incident X-ray beam, generally between 0.1 and $0.5^{\circ}$, the scattering experiment is now performed in a grazing-incidence geometry [part (c)], GISAXS or GIWAXS. Data obtained from these experiments are often presented in terms of the scattering vector $q=k_{\mathrm{f}}-k_{\mathrm{i}}$, which can be readily described in terms of $2 \theta$ by the expression $|q|=\left(\frac{4 \pi}{\lambda}\right) \sin \left(\frac{2 \theta}{2}\right)$, where $\lambda$ is the X-ray wavelength.

\section{KINETICS AND MECHANISMS OF HYBRID PEROVSKITE FILM FORMATION AND TRANSFORMATION}

Organic-inorganic metal halide (hybrid) perovskites have attracted widespread attention for PVs because of their exceptional photophysical properties. ${ }^{9,15-18}$ The scientific and technological value of this family of semiconductors is further enhanced by the relative ease of structural and chemical tunability, ${ }^{19-21}$ and the ability to obtain respectable performance metrics via a wide range of low-cost processing methods. ${ }^{22-25}$ Because of these characteristics, the wider field of perovskite optoelectronics is thriving, with notable results also obtained in the development of light-emitting devices. ${ }^{26-29}$ These extremely encouraging developments have been reviewed extensively elsewhere ${ }^{30}$; the purpose of this article is to draw attention to studies which have provided quantitative and time-resolved insight into the growth and transformation processes of perovskite semiconductor films.

Given their use in the initial proof-of-concept solar cells, the perovskites $\left(\mathrm{CH}_{3} \mathrm{NH}_{3}\right) \mathrm{PbX}_{3}$ (where $\mathrm{X}=\mathrm{I}, \mathrm{Cl}$, or $\mathrm{Br}$ ) arguably represent the workhorse materials of the field. ${ }^{31-33}$ The ability of the $\mathrm{ABX}_{3}$ perovskite crystal structure to tolerate multiple $\mathrm{A}, \mathrm{B}$, and $\mathrm{X}$ components provides a handle (by means of composition engineering) to fine-tune its semiconductor properties, ${ }^{20,21,34}$ enabling the design of single- and tandem-junction solar cells with optical bandgaps tuned for maximum solar energy harvesting. ${ }^{35,36}$ When outstanding device properties are reported, this results from the judicious optimization of high-quality semiconductor films on advanced electrode layers.

To form an organic-inorganic metal halide perovskite film, two or more precursor materials (a minimum of an organic- and a metal-halide) must undergo a conversion process. Because this can take place in the solid, vapor, or solution phase, the in-depth study of perovskite formation is naturally motivated to provide insight into its kinetics and the role played by any intermediate phases. Information gained by such studies is especially valuable for researchers in both academic and industry groups because of the benefits brought by working from reliable and well-understood processing protocols.

\section{A. Vapor deposition}

Preparing perovskite solar cells by vapor deposition of the precursors provides a means to realize uniform films over large areas with relative ease (Fig. 2). Having been first demonstrated by Liu et al., who achieved PCEs of up to $15 \%,{ }^{37}$ the process was monitored in situ using XRD by Pistor et al. ${ }^{38}$ In both cases, the perovskite $\mathrm{CH}_{3} \mathrm{NH}_{3} \mathrm{~Pb}$ $\left(\mathrm{I}_{x} \mathrm{Cl}_{1-x}\right)_{3}$ was formed by co-deposition of $\mathrm{CH}_{3} \mathrm{NH}_{3} \mathrm{I}$ and $\mathrm{PbCl}_{2}$, with the halide stoichiometry controlled by the relative flux of each precursor. For low $\mathrm{PbCl}_{2}$ fluxes (corresponding to a source temperature below c. $450{ }^{\circ} \mathrm{C}$ ), an optically dense film can be produced, with an optical band gap $E_{\mathrm{g}}(\sim 1.6 \mathrm{eV})$ and lattice parameter $a(6.288 \AA)$ that are close to thin films of the pure triiodide perovskite. ${ }^{39-41}$ Whereas crystals of $\mathrm{CH}_{3} \mathrm{NH}_{3} \mathrm{PbI}_{3}$ exhibit tetragonal symmetry at room temperature, the deposited $\mathrm{CH}_{3} \mathrm{NH}_{3} \mathrm{~Pb}\left(\mathrm{I}_{x} \mathrm{Cl}_{1-x}\right)_{3}$ films were found to exhibit cubic symmetry; a characteristic that was suggested to result from the presence of $\mathrm{Cl}$ that reduces the cubic-tetragonal phase transition temperature and stabilizes the cubic 

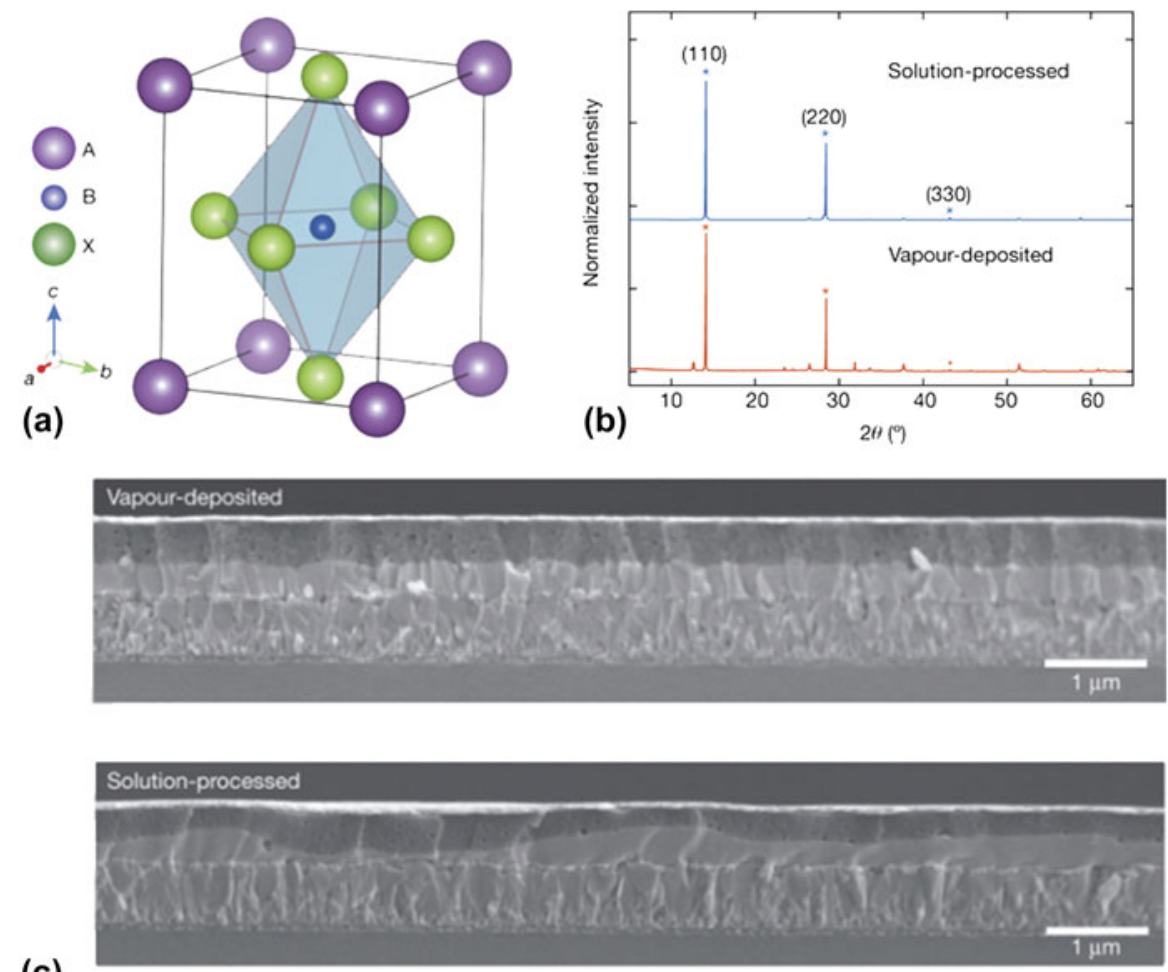

(c)

FIG. 2. (a) Schematic crystal structure of an $\mathrm{ABX}_{3}$ perovskite, where the $\mathrm{A}$ cation surrounds $\mathrm{X}$ anions in corner-sharing $\mathrm{BX}$ octohedra. Parts (b) and (c) show XRD and scanning electron microscopy data for $\mathrm{CH}_{3} \mathrm{NH}_{3} \mathrm{~Pb}\left(\mathrm{I}_{x} \mathrm{Cl}_{1-x}\right)_{3}$, respectively, highlighting the differences in film uniformity between vapor- and solution-processing routes. Reprinted with permission from Ref. 37. Copyright 2013 Nature Publishing Group.
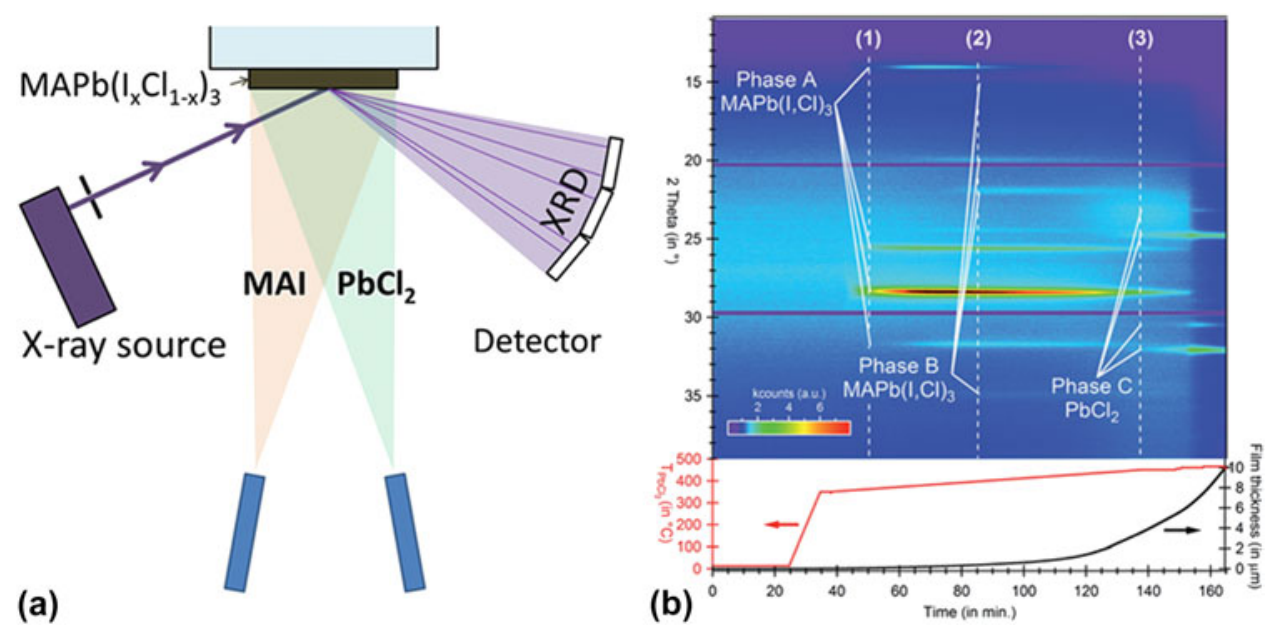

FIG. 3. Schematic setup [part (a)] and in situ XRD data [part (b)] for $\mathrm{CH}_{3} \mathrm{NH}_{3} \mathrm{~Pb}\left(\mathrm{I}_{x} \mathrm{Cl}_{1-x}\right)_{3}\left(\mathrm{MAPb}(\mathrm{I}, \mathrm{Cl})_{3}\right)$ perovskite during a temperature ramp of the $\mathrm{PbCl}_{2}$ source. At relatively high $\mathrm{PbCl}_{2}$ fluxes, a chlorine-rich perovskite phase (Phase B) preferentially forms over an iodine-rich perovskite (Phase A). Reprinted with permission from Ref. 38. Copyright 2014 American Chemical Society.

phase under ambient conditions. ${ }^{42}$ Increasing the $\mathrm{PbCl}_{2}$ deposition rate predictably increases the concentration of $\mathrm{Cl}$ in the deposited film, as data in Fig. 3 show. Crucially this process does not allow for a continuous tuning of the halide ratio in the perovskite, in contrast to $\mathrm{I}-\mathrm{Br}$ mixedhalide systems. ${ }^{43}$ Instead, a miscibility gap existsestimated between $0.95>x>0.5$ based on XRD data alone-which may be explained by the relatively large difference in ionic radii between $\mathrm{I}$ and $\mathrm{Cl}$. Postdeposition thermal annealing permits recrystallization of the perovskite, including an enhancement of crystallite orientation that is initially defined by the deposition step. Such findings open up the possibility to fabricate solar cells with efficiencies beyond what can be achieved by vapor 
deposition alone. $^{31}$ At sample temperatures above $200{ }^{\circ} \mathrm{C}$, degradation of the perovskite into products including $\mathrm{PbI}_{2}$ was determined. Importantly this experiment did not focus on the effects of isothermal annealing; indeed heat-induced degradation at lower temperatures is often observed and will be discussed later in this review.

\section{B. Solution deposition}

The observed miscibility gap between iodine- and chlorine-rich perovskites strongly supports the large body of the literature on solution-processed $\mathrm{CH}_{3} \mathrm{NH}_{3} \mathrm{~Pb}$ $\left(\mathrm{I}_{x} \mathrm{Cl}_{1-x}\right)_{3}$. Although $\mathrm{Cl}$ inclusion has been shown to impart favorable optoelectronic properties to the semiconductor, ${ }^{44,45}$ initial studies generated a level of surprise amongst the research community because of the large difference in halide stoichiometries between the precursors and the final films, leading to sometimes inconsistent reports on the precise amount of $\mathrm{Cl}$ in the latter. ${ }^{46-48}$ Compared to vapor deposition methods, wet processing adds additional complexity through the dynamics of film formation and the compositions and thermal histories of any solutions used. If not controlled, these factors can increase the likelihood of local inhomogeneities and voids in the prepared semiconductor film that may impact negatively on optoelectronic performance.

Common routes for solution-processed perovskite films include the deposition of a mixed precursor ink followed by a thermal anneal ${ }^{31}$ and the sequential deposition of the metal- and organic-halides ${ }^{32}$ (Fig. 4 shows the example case of $\mathrm{CH}_{3} \mathrm{NH}_{3} \mathrm{PbI}_{3}$ ). These are routinely referred to as "one-step" and "two-step" processing methods, respectively, in the perovskite PV literature and are considered in turn in this review.

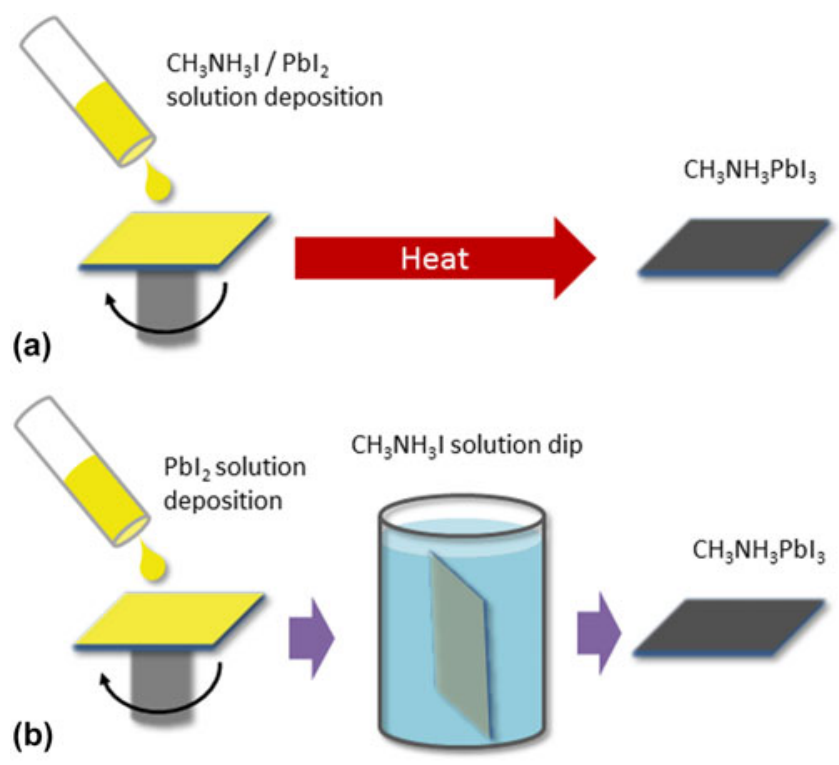

FIG. 4. Comparison of one-step [part (a)] and two-step [part (b)] methods for the preparation of a perovskite thin film.

\section{C. "One-step" processing}

Initial studies on solution processed $\mathrm{CH}_{3} \mathrm{NH}_{3} \mathrm{~Pb}$ $\left(\mathrm{I}_{x} \mathrm{Cl}_{1-x}\right)_{3}$ described the use of a precursor ink containing $\mathrm{CH}_{3} \mathrm{NH}_{3} \mathrm{I}$ and $\mathrm{PbCl}_{2}$ dissolved at a 3:1 molar ratio in dimethylformamide (DMF) when preparing efficient PV cells. ${ }^{31}$ In itself the solution deposition step, when performed at ambient temperature, does not drive the complete conversion of the precursors. XRD measurements by Dualeh et al. on films dried at $25{ }^{\circ} \mathrm{C}$ indicated a number of unknown oxidized and/or hydrated phases within the sample alongside unreacted $\mathrm{PbCl}_{2}{ }^{49}$ The relative ratios of each phase depend not only on the history of the solution and the film formation step but also the conditions of the local environment. For example, in otherwise dry atmospheres, 3:1 mol\% $\mathrm{CH}_{3} \mathrm{NH}_{3} \mathrm{I}: \mathrm{PbCl}_{2}$ precursor films will have a yellow hue that is indicative of $\mathrm{PbI}_{2}$ formation. When moisture is present in the atmosphere, these films will evolve in color and film morphology to a partially hydrated phase because of the hygroscopic nature of the organic halide. ${ }^{50,51}$ Although the exact structures within these samples are difficult to characterize unambiguously, what is known is that the exposure to humid atmospheres has a major impact on the perovskite formation process and the semiconductor properties of the final sample. ${ }^{50}$ In one study by Unger et al., the researchers evidenced the formation of needle-like crystals $10-100 \mu \mathrm{m}$ in size in 3:1 mol\% $\mathrm{CH}_{3} \mathrm{NH}_{3} \mathrm{I}: \mathrm{PbCl}_{2}$ precursor films left in ambient conditions over one hour, ${ }^{52}$ with such structures broadly maintaining their macroscopic shape and size after annealing at $100{ }^{\circ} \mathrm{C}$. These observations were supported by the work of Barrows et al., ${ }^{53}$ who confirmed the reappearance of the yellow phase during the temperature ramp of the thermal annealing process.

Through these studies and several others, ${ }^{49,54-59}$ the conversion of $3: 1 \mathrm{~mol} \% \mathrm{CH}_{3} \mathrm{NH}_{3} \mathrm{I}: \mathrm{PbCl}_{2}$ to $\mathrm{CH}_{3} \mathrm{NH}_{3} \mathrm{~Pb}$ $\left(\mathrm{I}_{x} \mathrm{Cl}_{1-x}\right)_{3}$ via thermal annealing has been characterized in situ using XRD, GIWAXS, and GISAXS techniques. During the temperature ramp, and at temperatures below $70{ }^{\circ} \mathrm{C}$, slow conversion of the precursor intermediates into the target perovskite composition takes place (i.e., complete conversion requires an isothermal annealing time of several hours ${ }^{49}$ ). Residual solvent may evaporate during this stage for films that have not been completely dried after solution casting. At temperatures around $50-70{ }^{\circ} \mathrm{C}$, formation of metastable $\mathrm{PbI}_{2}$ and $\mathrm{CH}_{3} \mathrm{NH}_{3} \mathrm{PbCl}_{3}$ crystallites begins to take place, their size being partly determined by the temperature ramp rate. ${ }^{57}$ Ex situ work by Williams et al. has shown that the Cl-rich perovskite phase acts as a template for the final sample morphology. ${ }^{60}$ As the sample temperature continues to rise these processes precede and eventually drive the accelerated formation of the more stable $\mathrm{CH}_{3} \mathrm{NH}_{3} \mathrm{~Pb}$ $\left(\mathrm{I}_{x} \mathrm{Cl}_{1-x}\right)$ phase, with chlorine present at a halide concentration of a few $\%$ or less. ${ }^{58}$ Isothermal annealing 
experiments in the temperature range $80-120{ }^{\circ} \mathrm{C}$ have been used to determine an activation energy of roughly $85 \mathrm{~kJ} / \mathrm{mol}^{53,54}$ for this transformation. At these temperatures excess $\mathrm{CH}_{3} \mathrm{NH}_{3} \mathrm{Cl}$ is removed from the film by sublimation, a process may be partly rationalized by the low miscibility between $\mathrm{Cl}$ - and I-rich perovskite phases as discussed earlier. Film densification also takes place during this time, alongside changes in the aspect ratio and orientation of perovskite grains. ${ }^{53,59}$ These steps are summarized in Figs. 5 and 6 below.
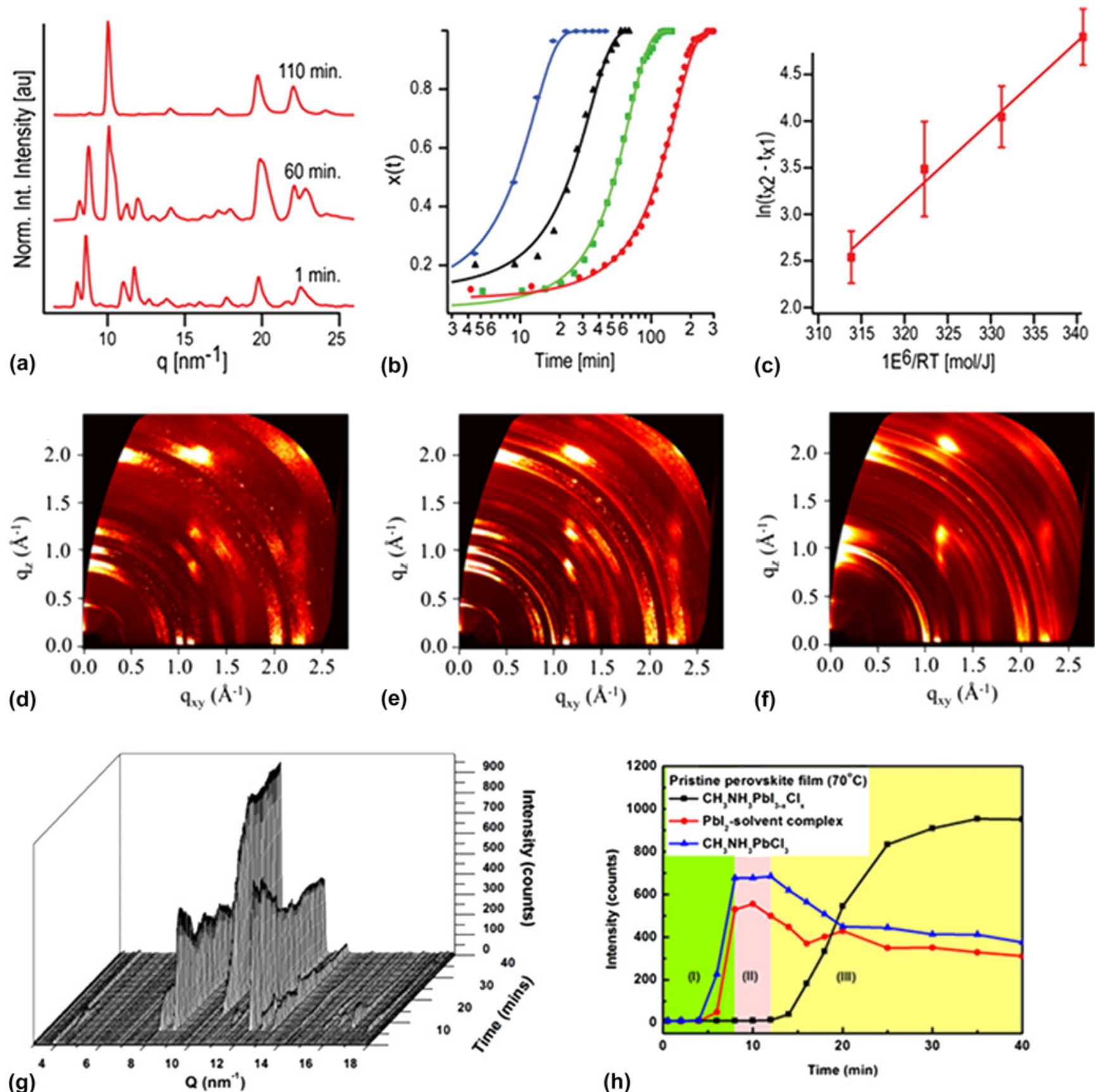

FIG. 5. Overview of "one-step" formation of $\mathrm{CH}_{3} \mathrm{NH}_{3} \mathrm{~Pb}\left(\mathrm{I}_{x} \mathrm{Cl}_{1-x}\right)_{3}$ perovskite, as inferred from in situ GIWAXS measurements. (a) Azimuthally integrated GIWAXS patterns corresponding to the precursor, intermediate, and perovskite phases during an isothermal annealing step at $90{ }^{\circ} \mathrm{C}$. Parts (b) and (c) detail the growth kinetics of the perovskite phase — determined from the intensity of the [110] perovskite reflection at $q \sim 1 \AA^{-1}$-for isothermal annealing temperatures between 80 and $110^{\circ} \mathrm{C}$. Reprinted with permission from Ref. 54. Copyright 2015 American Chemical Society. Insight into the evolution of crystal grain orientation is provided in parts (d)-(f), where the presented 2D GIWAXS patterns correspond to the precursor phase (d), an intermediate phase containing $50 \% \mathrm{CH}_{3} \mathrm{NH}_{3} \mathrm{~Pb}\left(\mathrm{I}_{x} \mathrm{Cl}_{1-x}\right)_{3}$ (e), and the fully formed $\mathrm{CH}_{3} \mathrm{NH}_{3} \mathrm{~Pb}\left(\mathrm{I}_{x} \mathrm{Cl}_{1-x}\right)_{3}$ phase (f) during a $80{ }^{\circ} \mathrm{C}$ isothermal anneal. Reprinted from Ref. 53 under a Creative Commons BY 4.0 license. In situ GIWAXS patterns for a drop-cast sample annealed at $70{ }^{\circ} \mathrm{C}$ are shown in part (g) with the corresponding kinetics shown in (h). Reprinted with permission from Ref. 58. Copyright 2016 American Chemical Society. 
The formation of low defect-density $\mathrm{CH}_{3} \mathrm{NH}_{3} \mathrm{~Pb}$ $\left(\mathrm{I}_{x} \mathrm{Cl}_{1-x}\right)$ films is achieved by annealing the sample for between one and two hours in the temperature range 80 $120^{\circ} \mathrm{C}$, where higher annealing temperatures increase the kinetics of the crystallization process. ${ }^{53,61}$ The quality of the formed perovskite layer can also be affected by the porosity of the substrate (a factor that is important in the manufacture of flexible solar cells), as small volumes of solvent and organic material can be absorbed during precursor casting. ${ }^{25,56}$ Although the annealing temperature ramp rate is not widely reported in device studies, Xu et al. have shown that gradual annealing facilitates enhanced solar cell efficiencies through the creation of compact perovskite films, alongside a controllable $\mathrm{Cl}$ concentration within the miscibility limit. ${ }^{62,63}$ When longer annealing times or annealing temperatures above this range are used, the formed perovskite undergoes irreversible decomposition through the removal of volatile organic material. As a consequence, $\mathrm{PbI}_{2}$ becomes the dominant phase within the film. Figure 7 illustrates the general evolution in $\mathrm{CH}_{3} \mathrm{NH}_{3} \mathrm{~Pb}\left(\mathrm{I}_{x} \mathrm{Cl}_{1-x}\right)_{3}$ film formation and decomposition during a continuous temperature ramp.
In circumstances where halide loss out-competes perovskite crystallization, the likelihood for nonperovskite phases to exist in the final sample increases. A detailed discussion on whether such phases are beneficial for semiconductor optoelectronic performance and device stability is beyond the scope of this review. ${ }^{64-66}$ What is clear however is that the sample stoichiometry and defect density are not only determined by the casting solution but also by the local environment during annealing. For example, annealing in an atmosphere rich in organic halide provides an external source of precursor that can compensate for any excessive precursor loss from the sample. ${ }^{67,68}$ Likewise, annealing in a solvent rich atmosphere provides an alternative means to achieve fully grown perovskite films, through the suppressed solvent evaporation rate and the associated extended precursor recrystallization time. ${ }^{69,70}$ These factors have yet to be investigated in-depth using time-resolved measurements on the sample structure. The exception to this are the studies on the effects of moisture, and since $\mathrm{CH}_{3} \mathrm{NH}_{3} \mathrm{I}$ is hygroscopic these experiments can be motivated either by a need to rationalize the processing
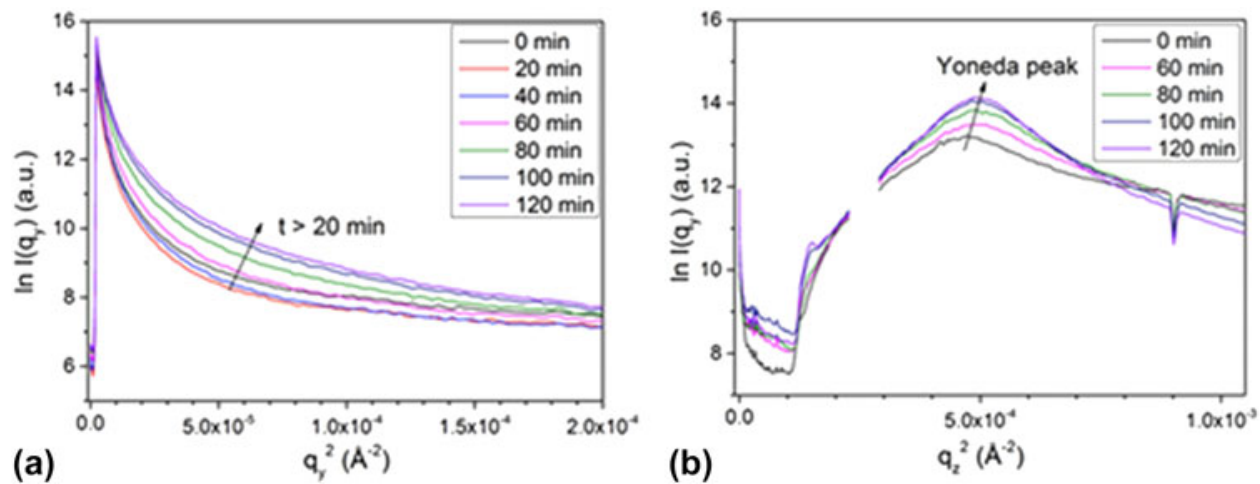

FIG. 6. In situ GISAXS data (Guinier plots) showing the evolution in one-step processed $\mathrm{CH}_{3} \mathrm{NH}_{3} \mathrm{~Pb}\left(\mathrm{I}_{x} \mathrm{Cl}_{1-x}\right)_{3}$ perovskite during a $80{ }^{\circ} \mathrm{C}$ isothermal anneal. Reprinted from Ref. 53 under a Creative Commons BY 4.0 license.

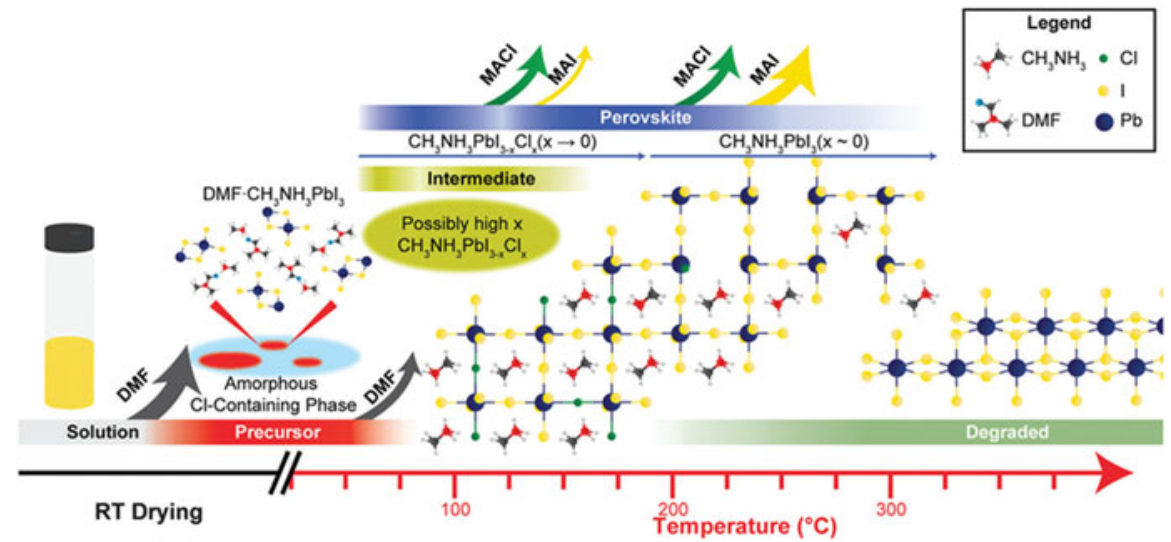

FIG. 7. Schematic representation of the main processes that take place during $\mathrm{CH}_{3} \mathrm{NH}_{3} \mathrm{~Pb}\left(\mathrm{I}_{x} \mathrm{Cl}_{1-x}\right)_{3}$ perovskite formation and degradation. The approximate relative intensity of X-ray scatter from each phase (proportional to its abundance in the sample) is represented by the intensity of the color bars. ${ }^{57}$ Reproduced by permission of The Royal Society of Chemistry. 
of perovskite films under ambient conditions or to characterize the effects of accelerated aging.

One of the first reports on the beneficial effects of preparing $\mathrm{CH}_{3} \mathrm{NH}_{3} \mathrm{~Pb}\left(\mathrm{I}_{x} \mathrm{Cl}_{1-x}\right)_{3}$ films in ambient conditions was provided by You et al. ${ }^{71}$ Under conditions of $35 \%$ relative humidity, a 3\% absolute increase in average device PCE over solar cells prepared in dry nitrogen (12\% initial PCE) was demonstrated. Scanning electron microscopy (SEM) measurements gave insight into this enhancement, showing improved perovskite surface coverage and larger grain sizes for the ambient processed films. By varying the relative humidity, a processing window for enhanced optoelectronic performance was identified; an upper bound of $\sim 80 \%$ is in good agreement with the work of Eperon et al. on the moisture-assisted growth of $\mathrm{CH}_{3} \mathrm{NH}_{3} \mathrm{PbI}_{3}$ thin films. ${ }^{50}$ Both groups suggested that the underlying mechanism for the improved perovskite film quality was the increase in $\mathrm{CH}_{3} \mathrm{NH}_{3} \mathrm{I}$ mobility, which out-competes its evaporation and removal from the sample within the optimum humidity range. The accumulation of water molecules in grain boundaries may also enable larger crystallites to form via boundary creep between smaller grains. ${ }^{72}$

It is important to recognize that the benefits of 'selfhealing' can also be realized postperovskite formation, whereby films that have been initially prepared in dry conditions are exposed to low levels of moisture during a second annealing step. ${ }^{73}$ A key factor in either treatment is the stoichiometry of the precursor mixture; work on $\mathrm{CH}_{3} \mathrm{NH}_{3} \mathrm{PbI}_{3}$ has shown that if excess of $\mathrm{PbI}_{2}$ is present in the precursor film its ability to withstand moisture-induced perovskite decomposition is improved compared to samples prepared using equal quantities of organic and inorganic halides (Fig. 8). ${ }^{73}$ From this result, it was proposed that $\mathrm{PbI}_{2}$ acts as a protective barrier layer for $\mathrm{CH}_{3} \mathrm{NH}_{3} \mathrm{PbI}_{3}$ grains, residing at the surface and/or terminal positions of perovskite grains due to its delayed crystallization following precursor conversion. Understandably, films prepared using excess $\mathrm{CH}_{3} \mathrm{NH}_{3} \mathrm{I}$ exhibited the slowest formation of $\mathrm{PbI}_{2}$ degradation products during perovskite formation, and in the presence of moisture also underwent the largest changes in film morphology during a second annealing treatment, in agreement with previous studies. The positive outcome from this study was the clear demonstration of the interplay between perovskite precursor compositions, the benefits (if any) that can be brought by moistureassisted perovskite formation, and the long-term stability of the final sample.

\section{The role of precursor materials and casting solvents}

The previous analysis provides a foundation on which to consider more widely how different precursor materials, stoichiometries, and casting solvents impact upon the quality of $\mathrm{CH}_{3} \mathrm{NH}_{3} \mathrm{~Pb}\left(\mathrm{I}_{x} \mathrm{Cl}_{1-x}\right)_{3}$ and $\mathrm{CH}_{3} \mathrm{NH}_{3} \mathrm{PbI}_{3}$ films. Studies on the role of the lead anion by Weisner, Snaith, and co-workers showed how the thermal budget associated with precursor conversion can be reduced by using lead salts with high volatility. ${ }^{54,74}$ Specifically, $\mathrm{CH}_{3} \mathrm{NH}_{3} \mathrm{PbI}_{3}$ films prepared by lead acetate $\left(\mathrm{PbAc}_{2}\right)$ rather than $\mathrm{PbI}_{2}$ required shorter annealing times and facilitated the formation of ultra-smooth perovskite films with almost total substrate coverage. ${ }^{74}$ Average solar cell PCE metrics were $14 \%$ and $12 \%$, respectively. $\mathrm{PbAc}_{2}$-route $\mathrm{CH}_{3} \mathrm{NH}_{3} \mathrm{PbI}_{3}$ films were further characterized by a weak preferential ordering of crystal domains, a feature that may be explained by the faster rate of precursor transformation, in addition to enhanced thermal stability as judged by the delayed emergence of $\mathrm{PbI}_{2}$ during extended isothermal annealing. For the most volatile lead anion, lead nitrate, the perovskite crystal growth can even take place at ambient temperature, leading to potentially uncontrolled perovskite growth and poor device efficiencies.

Insight into the role of chlorine on the perovskite formation process was provided by Nenon et al. who studied the formation of drop-cast $\mathrm{CH}_{3} \mathrm{NH}_{3} \mathrm{~Pb}\left(\mathrm{I}_{x} \mathrm{Cl}_{1-x}\right)_{3}$ films from different precursors and organic- to inorganichalide stoichiometries (Fig. 9) ${ }^{57}$ During thermal annealing, a key difference in perovskite formation when $\mathrm{Cl}$ was present was the existence of a relatively crystalline Cl-rich intermediate perovskite phase at temperatures above $50{ }^{\circ} \mathrm{C}$ that mediated the growth of iodine rich $\mathrm{CH}_{3} \mathrm{NH}_{3} \mathrm{~Pb}\left(\mathrm{I}_{x} \mathrm{Cl}_{1-x}\right)_{3}$ at temperatures above $70{ }^{\circ} \mathrm{C}$. By noting the differences in the abundance of each precursor phase when comparing drop-cast films with films prepared via spin-coating, it was suggested that high-quality perovskite films can be realized by exerting greater kinetic control over the sample during precursor solution deposition, as well as during the early stages of the thermal annealing step (e.g., the temperature ramp). The presence of $\mathrm{Cl}$ also impacts upon the kinetics of perovskite breakdown at higher temperatures, in addition to influencing the yield of degradation by-products. As can be seen in Fig. 9, films of $\mathrm{CH}_{3} \mathrm{NH}_{3} \mathrm{~Pb}\left(\mathrm{I}_{x} \mathrm{Cl}_{1-x}\right)_{3}$ prepared using either 1:1:1 mol\% $\mathrm{CH}_{3} \mathrm{NH}_{3} \mathrm{I}: \mathrm{CH}_{3} \mathrm{NH}_{3} \mathrm{Cl}: \mathrm{PbI}_{2}$ or $3: 1 \mathrm{~mol} \%$ $\mathrm{CH}_{3} \mathrm{NH}_{3} \mathrm{I}: \mathrm{PbCl}_{2}$ precursor stoichiometries undergo thermally induced decomposition before films of the pure triiodide. Although the onset temperatures for decomposition differ by roughly $40{ }^{\circ} \mathrm{C}$ the rate of perovskite breakdown is significantly faster for $\mathrm{CH}_{3} \mathrm{NH}_{3} \mathrm{PbI}_{3}$, with $\mathrm{PbI}_{2}$ forming rapidly as a result. Such findings potentially provide a foundation on which the interplay between perovskite- and non-perovskite phases in governing the optoelectronic properties of aged devices-particularly those subject to thermal stresses - can be understood.

A vital outcome from the Nenon study was the observed difference in precursor abundance in drop-cast 


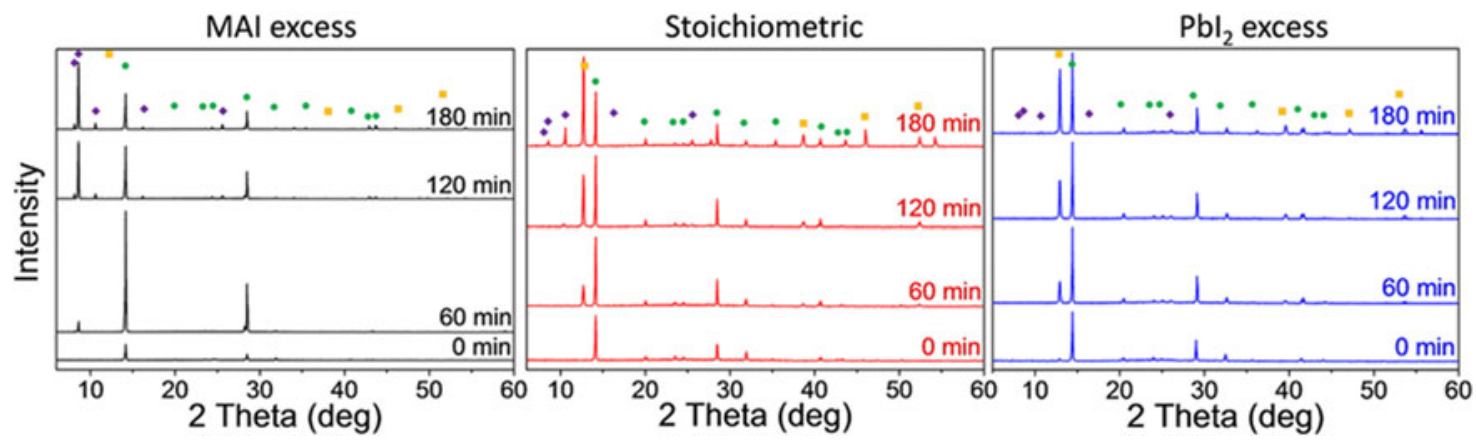

FIG. 8. Time-resolved XRD measurements of $\mathrm{CH}_{3} \mathrm{NH}_{3} \mathrm{PbI}_{3}$ perovskite thin films during postformation hydration under conditions of $90 \%$ relative humidity $/ 25{ }^{\circ} \mathrm{C}$. Perovskite films were initially prepared using stoichiometric mixtures of $\mathrm{CH}_{3} \mathrm{NH}_{3} \mathrm{I}$ and $\mathrm{PbI}_{2}$ or $5 \%$ molar excess of either. Green, purple, and yellow symbols correspond to $\mathrm{CH}_{3} \mathrm{NH}_{3} \mathrm{PbI}_{3}, \mathrm{PbI}_{2}$, and $\mathrm{CH}_{3} \mathrm{NH}_{3} \mathrm{PbI}_{3} \cdot \mathrm{H}_{2} \mathrm{O}$ phases respectively, and clarify the different onsets of perovskite degradation. Figure reprinted with permission from Ref. 73. Copyright 2016 Wiley-VCH.
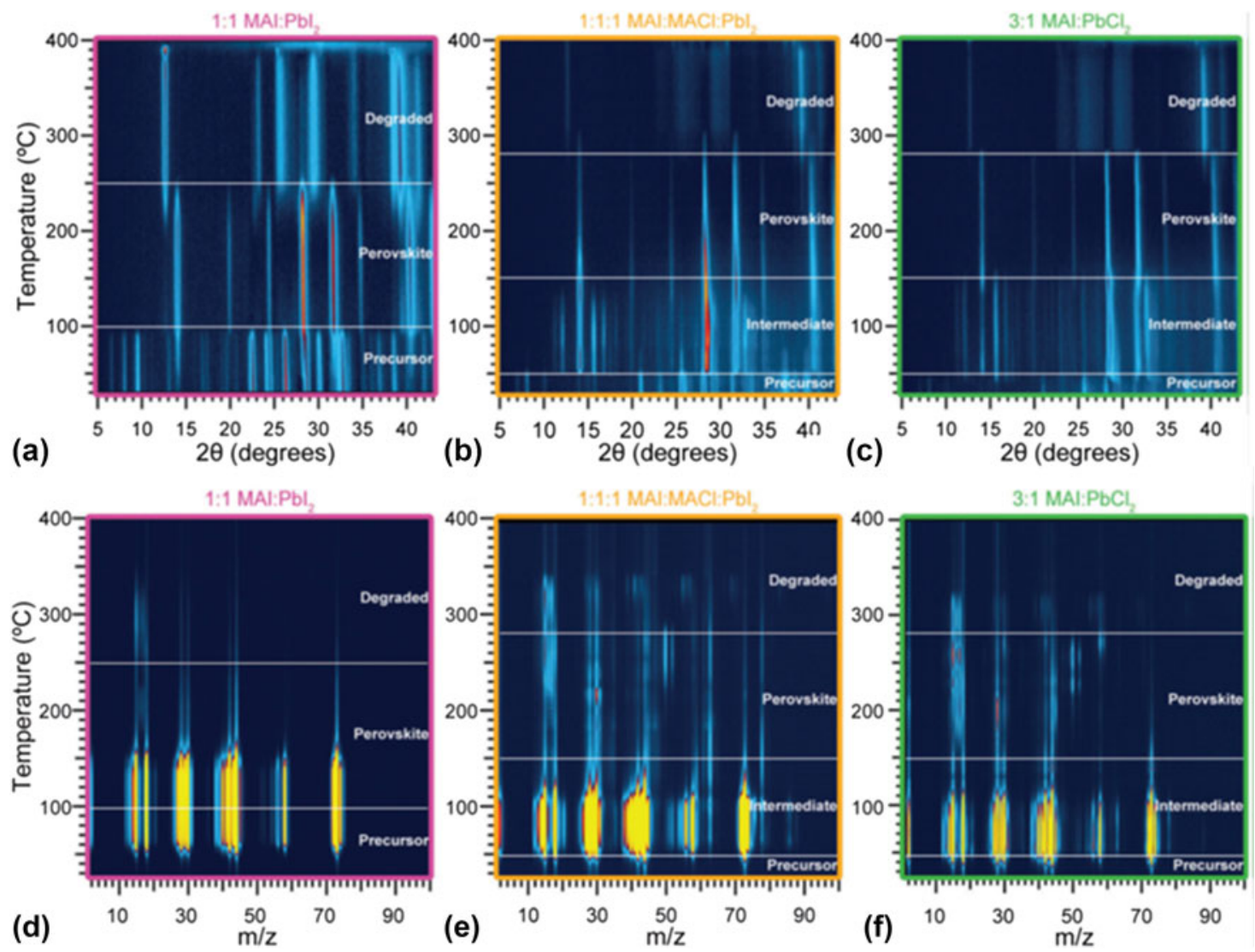

FIG. 9. (a)-(c) In situ temperature-dependant $\mathrm{XRD}$ scans of drop-cast perovskite precursor solutions prepared using $1: 1 \mathrm{~mol}^{2} \mathrm{CH}_{3} \mathrm{NH}_{3} \mathrm{I}(\mathrm{MAI})$ $\mathrm{PbI}_{2}$, mol\% 1:1:1 $\mathrm{CH}_{3} \mathrm{NH}_{3} \mathrm{I}: \mathrm{CH}_{3} \mathrm{NH}_{3} \mathrm{Cl}(\mathrm{MACl}): \mathrm{PbI}_{2}$, or 3:1 mol\% $\mathrm{CH}_{3} \mathrm{NH}_{3} \mathrm{I}: \mathrm{PbCl}_{2}$. In parts (d)-(f), the same precursor samples are subject to in situ temperature-programmed desorption mass spectrometry (TPD-MS) measurements that provide insight into the loss of organic material during heating. ${ }^{57}$ Reproduced by permission of The Royal Society of Chemistry.

films relative to those prepared by spin-coating, proving the relationship between precursor intermediate sample phases, film drying dynamics, and the final perovskite structure. Such relationships are a crucial component in solar cell process optimization and in the medium-term, research of this type also helps to rationally design scalable processing methods-where any given technique can involve distinct film formation dynamics-to maintain device performance parity. As an optimization strategy therefore, solvent engineering is a valuable approach to realizing low defect-density semiconductor films with high performance metrics. ${ }^{75}$ Although in situ experiments are less developed in this area, an analysis of significant ex situ sample characterization papers is instructive to appreciate how future studies may be inspired. 
The first detailed report on the effects of different casting solvents evidenced a link between slowly dried precursor films, specifically those cast from relatively high boiling-point (b.p.) solvents such as dimethyl sulfoxide (DMSO), and hybrid perovskite layers containing voids and other large-scale thickness non-uniformities. ${ }^{61}$ Upon integration into a solar cell device, such films facilitated significant electrical shorting (amongst other negative effects) and as a result PCEs were poor. To maximize the crystal grain size as well as overall surface coverage, low b.p. solvents are preferred. Within the literature on single precursor casting solvents, a recent study by Noel et al. has shown how acetonitrile can be used to prepare pinhole-free, highly specular $\mathrm{CH}_{3} \mathrm{NH}_{3} \mathrm{PbI}_{3}$ films over areas exceeding 100 $\mathrm{cm}^{2}$ and solar cells with PCEs of up to $18 \% .^{76}$ To realize these positive sample characteristics, acetonitrile must be first mixed with methylamine gas to facilitate its dissolution of the precursor lead salt, which would otherwise be insoluble.

Rather than working with a single casting solvent, the use of solvent additives provides an alternative approach to realizing high solar cell efficiencies. Diiodooctane (DIO) is one such example and can be used in perovskite solar cell fabrication by dissolving at a few vol\% in DMF. ${ }^{77,78}$ Generally characterized by its high boiling point and low volatility, the proposed mechanism for the benefits brought by DIO is its chelation with the precursor lead halide, which results in a modified and extended process of film formation. ${ }^{79,80}$ Given the relatively low $\mathrm{C}-\mathrm{I}$ bond strength $(\sim 50 \mathrm{kcal} / \mathrm{mol})$, during thermal annealing residual DIO in the cast film can provide an additional source of halide material to the precursor-perovskite transformation process. A follow-up study on a wider range of alkyl halide additives supported this model and demonstrated solar cell PCEs of up to $13 \%$ through synergistic improvements in the device open circuit-voltage $\left(V_{\mathrm{OC}}\right)$, short circuit-photocurrent density $\left(J_{\mathrm{SC}}\right)$, and fill factor $(\mathrm{FF})$, suggesting a route for fine control of halide stoichiometry and morphology in perovskite films. ${ }^{78}$ Elsewhere, the use of hypophosphorous acid (HPA) has been demonstrated to alter the volume fractions of perovskite- and non-perovskite phases within a $\mathrm{CH}_{3} \mathrm{NH}_{3} \mathrm{PbI}_{3}$ film by acting as a reducing agent for oxidized $\mathrm{I}_{2}$, a species that would otherwise favor the formation of metallic lead/charge recombination centers in the sample. ${ }^{81}$ Its ability to retard the crystallization dynamics of the perovskite can also result in large grains being formed, and as a consequence of both processes efficient solar cells can be realized (average stabilized power outputs for HPA-processed and reference solar cells were $13 \%$ and $7 \%$, respectively).

A final example of solvent engineering is solvent washing, which involves the deposition of a neat antisolvent such as toluene or chlorobenzene to the precursor film during casting. ${ }^{75,82,83}$ This step induces a rapid (few seconds) precipitation and partial-crystallization of precursor material, enabling the production of a uniform and compact film prior to the standard thermal annealing step. Although solvent washing is clearly beneficial for device performance, as relative efficiency improvements of up to $30 \%$ have been realized, its short duration may frustrate attempts to characterize its effects in situ. In Fig. 10, an overview of perovskite films processed via solvent engineering methods is presented.

\section{E. "Two-step" processing}

The sequential deposition of inorganic- and organichalide precursors potentially affords greater control over the final perovskite film morphology due to the intermediate preparation and optimization of the inorganic material (e.g., $\mathrm{PbI}_{2}$ ). Typically, the organic-halide is introduced to the inorganic film in the solution phase using a solvent that is orthogonal to the underlying layer. ${ }^{32}$ Vapor-phase deposition methods have also been shown to produce high-quality films with promising solar cell figures of merit. ${ }^{71}$ Insight into the dynamics of the solution-phase process was provided by Miyadera et al. who performed in situ GIWAXS measurements on $\mathrm{CH}_{3} \mathrm{NH}_{3} \mathrm{I}$ solutions drop-cast onto pre-made $\mathrm{PbI}_{2}$ films. ${ }^{84}$ As with the in situ GIWAXS studies on one-step processed perovskite films, an important observation in this work was the disruption in $\mathrm{PbI}_{2}$ grain orientation during perovskite formation, as can be seen in Fig. 11. For example, when $\mathrm{PbI}_{2}$ crystallites are initially highly orientated, as may be the case following vapor-phase deposition, $\mathrm{CH}_{3} \mathrm{NH}_{3} \mathrm{I}$ quickly disturbs this alignment by infiltrating and swelling the film. With increasing reaction time, the formation of relatively large perovskite grains is encouraged; note however that the density of the $\mathrm{PbI}_{2}$ layer plays a key role in governing the kinetics of process, as layers that are compact and relatively free of voids and pinholes require more time for $\mathrm{CH}_{3} \mathrm{NH}_{3} \mathrm{I}$ inclusion and reaction.

In a study that is complementary to the work in Ref. 84, the formation of $\mathrm{CH}_{3} \mathrm{NH}_{3} \mathrm{PbI}_{3}$ via diffusion of $\mathrm{CH}_{3} \mathrm{NH}_{3} \mathrm{I}$ vapor into pre-grown $\mathrm{PbI}_{2}$ was characterized by $\mathrm{Yang}$ et al. ${ }^{85}$ Here, both the lead-halide film and the $\mathrm{CH}_{3} \mathrm{NH}_{3} \mathrm{I}$ source were placed in a heated chamber within an XRD setup. During a continuous temperature ramp, the nucleation and early stage growth of $\mathrm{CH}_{3} \mathrm{NH}_{3} \mathrm{PbI}_{3}$ took place at temperatures exceeding $120{ }^{\circ} \mathrm{C}$. At higher temperatures $\left(200-240{ }^{\circ} \mathrm{C}\right)$, the crystallinity of $\mathrm{CH}_{3} \mathrm{NH}_{3} \mathrm{PbI}_{3}$ underwent a rapid increase before decomposing, indicative of late-stage grain reorientation and coalescence. Compared to 1-step processing of $\mathrm{CH}_{3} \mathrm{NH}_{3} \mathrm{~Pb}\left(\mathrm{I}_{x} \mathrm{Cl}_{1-x}\right)_{3}$, the activation energy for $\mathrm{CH}_{3} \mathrm{NH}_{3} \mathrm{PbI}_{3}$ formation via this route is much higher, at around $\sim 180 \mathrm{~kJ} / \mathrm{mol}$. Furthermore, the dominant growth mode of perovskite crystals is 
in-line with the expected pathways by which $\mathrm{CH}_{3} \mathrm{NH}_{3} \mathrm{I}$ infiltrates the $\mathrm{PbI}_{2}$ layer, i.e., surface initiated and further enabled by disruptions to crystal orientation that is induced by the perovskite growth process. These measurements provided a basis on which the growth dynamics of multiple mixed-halide perovskite films could be considered. For both mixed $\mathrm{I} / \mathrm{Br}$ and $\mathrm{I} / \mathrm{Cl}$ compositions, it was found that $\mathrm{CH}_{3} \mathrm{NH}_{3} \mathrm{PbI}_{3}$ was the preferred growth phase, a result that is rationalized by the relatively reactive nature of iodine. Data relating to the mixed $\mathrm{I} / \mathrm{Br}$

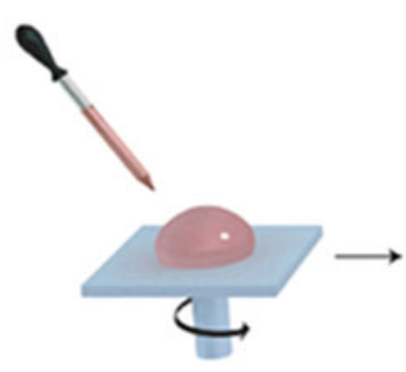

Perovskite solution

(a)

spreading

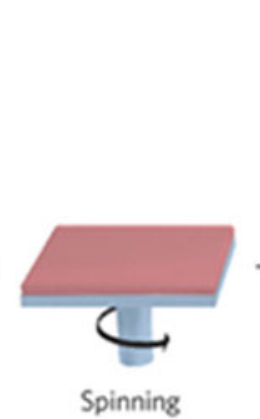

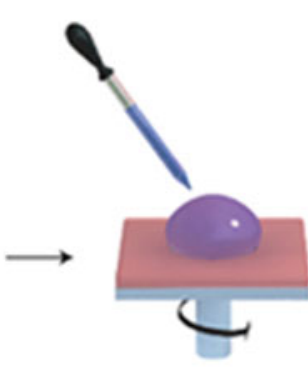

Toluene dripping

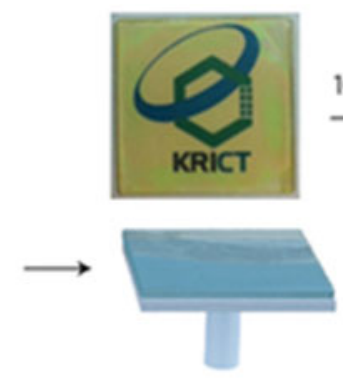

Intermediate phase film
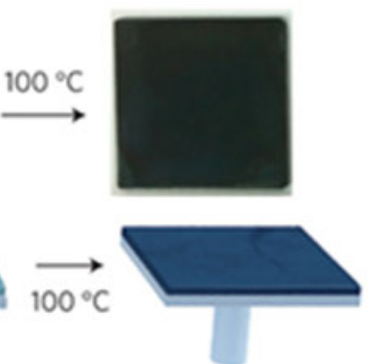

Dense and uniform perovskite film
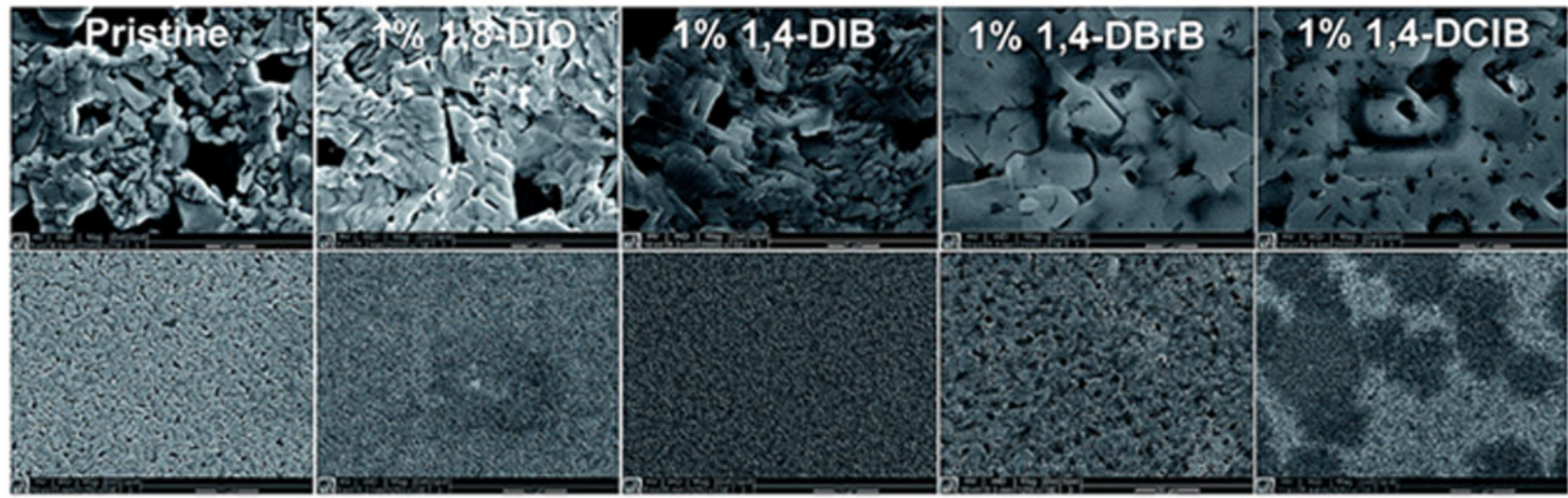

(b)

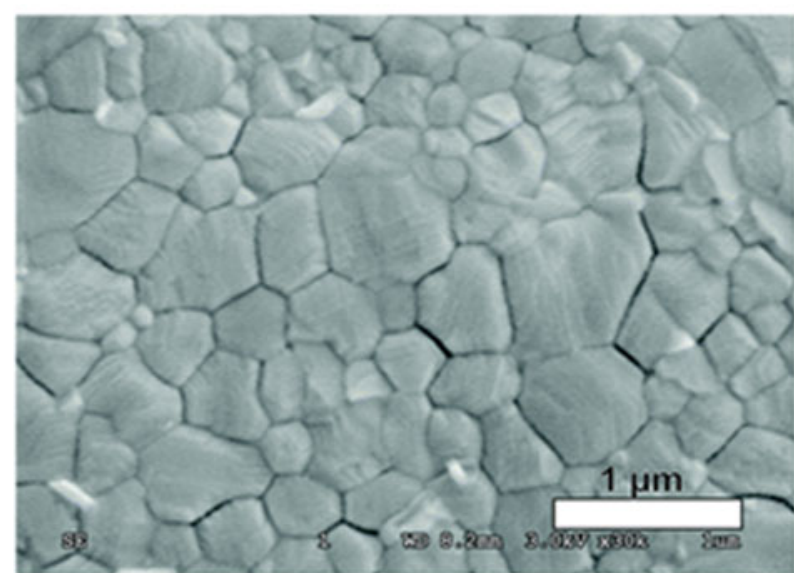

(c)

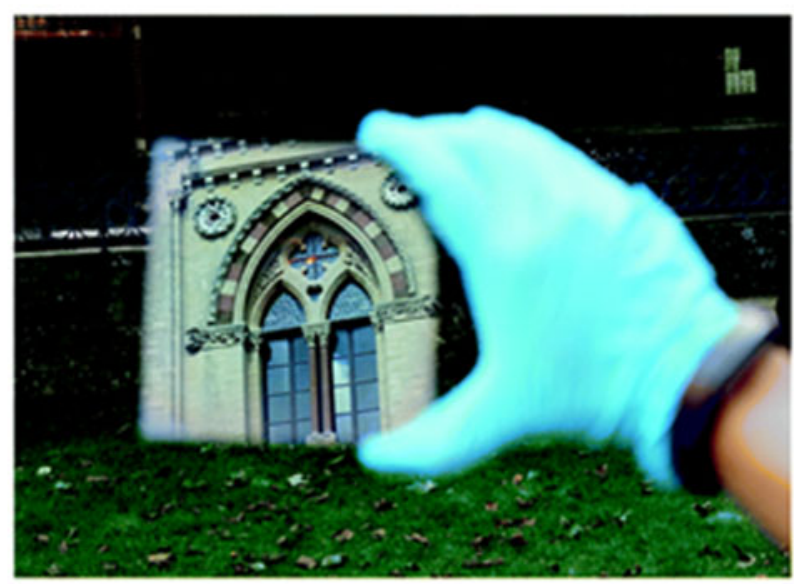

(d)

FIG. 10. Overview of solvent engineering methods that promote the formation of perovskite films with improved optoelectronic properties. Part (a) outlines the main steps in "one-step" processing of $\mathrm{CH}_{3} \mathrm{NH}_{3} \mathrm{~Pb}\left(\mathrm{I}_{1-x} \mathrm{Br}_{x}\right)_{3}$ perovskite films, with an additional step (the toluene drip) applied within the final $30 \mathrm{~s}$ of the precursor spin coating step. Reprinted with permission from Ref. 75 . Copyright 2014 Nature Publishing Group. In part (b), a series of scanning electron micrographs are presented for $\mathrm{CH}_{3} \mathrm{NH}_{3} \mathrm{PbI}_{3-x} \mathrm{Cl}_{x}$ films prepared using various alkyl-chain additives in the precursor solution, where the top row of images correspond to a field-of-view of approximately $5 \times 4 \mu \mathrm{m}^{2}$. ${ }^{78}$ Reproduced by permission of The Royal Society of Chemistry. Parts (c) and (d) correspond to films of $\mathrm{CH}_{3} \mathrm{NH}_{3} \mathrm{PbI}_{3}$ prepared using an acetonitrile/methylamine solution. ${ }^{76}$ Reproduced by permission of The Royal Society of Chemistry. 
sample are shown in Fig. 12. For the case of mixed I/Cl films, time-of-flight secondary ion mass spectroscopy (TOF-SIMS) imaging evidenced an in-plane network of $\mathrm{Cl}$-enriched regions that were presumed to correspond to $\mathrm{CH}_{3} \mathrm{NH}_{3} \mathrm{PbI}_{3}$ grain boundaries. Perhaps counterintuitively, $\mathrm{Br}$ and $\mathrm{Cl}$ facilitated the growth of larger $\mathrm{CH}_{3} \mathrm{NH}_{3} \mathrm{PbI}_{3}$ grains compared to samples prepared without the additional halide, providing supporting evidence to related studies that showed improved optoelectronic performance for films prepared via the mixed-halide route. ${ }^{44,45}$

\section{F. Other perovskites}

Substitution of methylammonium for formamidinium [ $\mathrm{HC}\left(\mathrm{NH}_{2}\right)_{2}$ or ' $\mathrm{FA}$ '] in lead halide perovskites is one example of composition engineering. ${ }^{86,87}$ Due to its larger size, the presence of FA cations within the perovskite lattice structure permits the preparation of semiconductors with relatively low band-gaps. The conditions in which the perovskite forms also change, with annealing temperatures (during "one-step processing") above $130{ }^{\circ} \mathrm{C}$ being used for precursor transformation. Aguiar et al. provided insight into this process for films of $\mathrm{FAPbI}_{3}$ using in situ XRD alongside in situ transmission electron microscopy (TEM) ${ }^{88}$ Between the onset temperature for perovskite formation and $\sim 175{ }^{\circ} \mathrm{C}$, the growth of $\mathrm{FAPbI}_{3}$ crystallites takes place alongside the growth of crystalline $\mathrm{PbI}_{2}$ (Fig. 13), with the latter residing at the perovskite grain boundaries as determined by TEM. Complementary valence electron energy loss
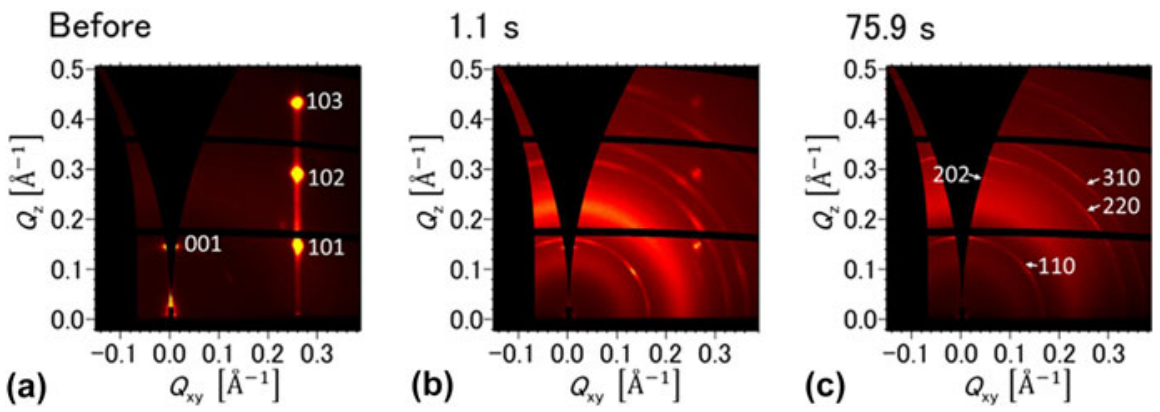

FIG. 11. In situ GIWAXS characterization of $\mathrm{CH}_{3} \mathrm{NH}_{3} \mathrm{PbI}_{3}$ perovskite during two-step processing. (a) GIWAXS pattern for a vacuum-deposited $\mathrm{PbI}$ thin film before $\mathrm{CH}_{3} \mathrm{NH}_{3} \mathrm{I}$ drop-casting. Parts (b) and (c) correspond to the same sample shortly after drop-casting and at a later time where diffraction features relating to the perovskite can be identified. Reprinted with permission from Ref. 84. Copyright 2015 American Chemical Society.
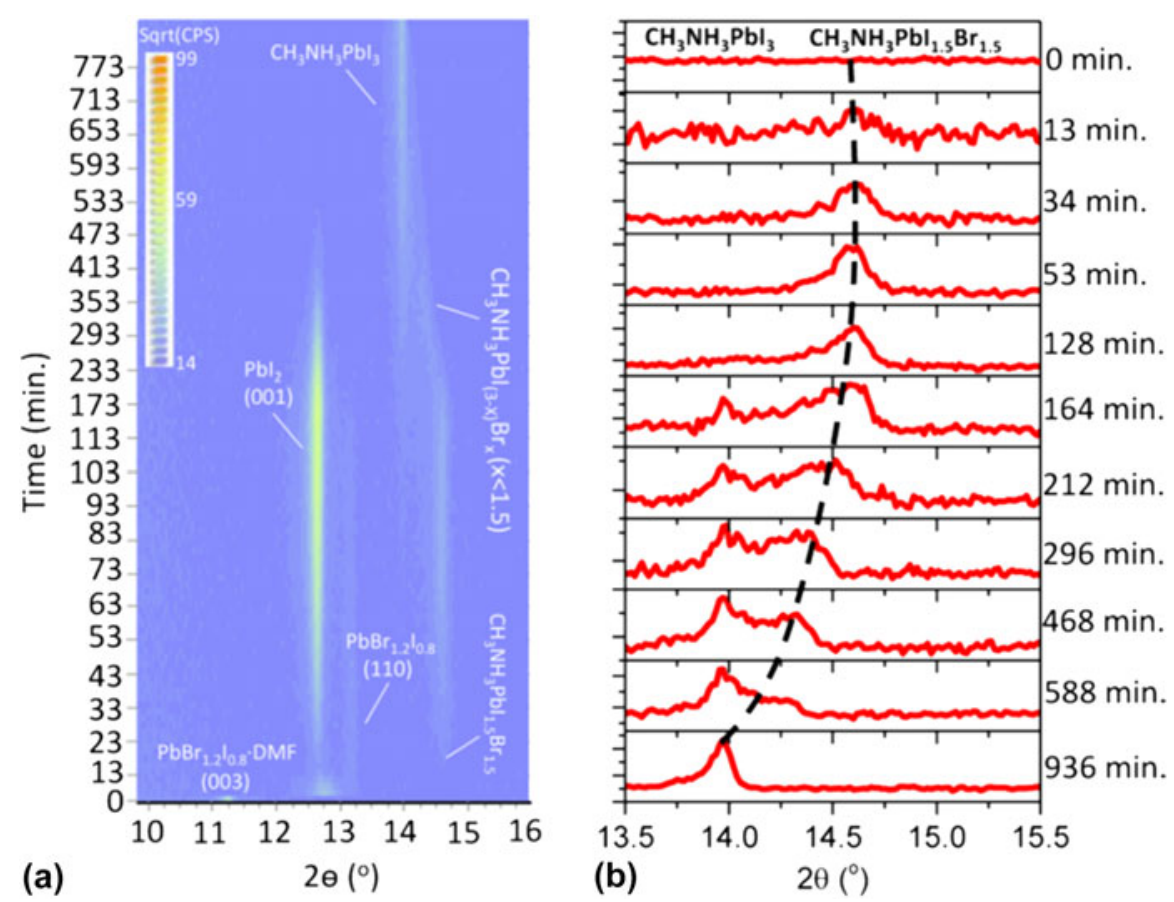

FIG. 12. In situ $\mathrm{XRD}$ scans of vapor-phase grown $\mathrm{CH}_{3} \mathrm{NH}_{3} \mathrm{~Pb}\left(\mathrm{I}_{1-x} \mathrm{Br}_{x}\right)_{3}$ films. Here, the temperature of the environment is $120{ }^{\circ} \mathrm{C}$ and the composition of the initial lead halide film is $\mathrm{PbBr}_{1.2} \mathrm{I}_{0.8}$. The data show that with increasing reaction time, the formation of $\mathrm{CH}_{3} \mathrm{NH}_{3} \mathrm{PbI}_{3}$ is favored. Reprinted with permission from Ref. 85. Copyright 2016 American Chemical Society. 


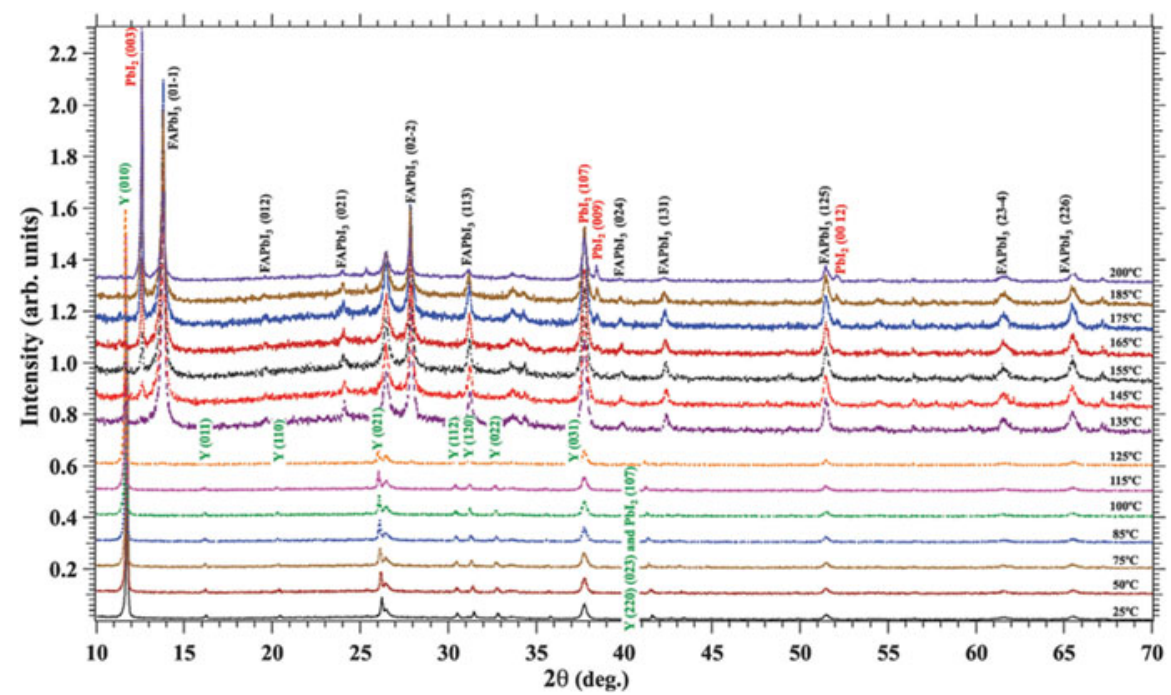

FIG. 13. In situ XRD patterns of $\mathrm{FAPbI}_{3}$ formation and degradation, with peaks labeled according to each crystalline phase. ${ }^{88}$ Reproduced by permission of The Royal Society of Chemistry.

(VEEL) spectroscopy measurements correlated the spatial distribution of $\mathrm{PbI}_{2}$ with hydroxyl species, suggesting a pathway by which water molecules may penetrate and potentially degrade the entire sample. During sample thermal annealing, whilst films of $\mathrm{CH}_{3} \mathrm{NH}_{3} \mathrm{PbI}_{3}$ would quickly degrade at these temperatures, films of $\mathrm{FAPbI}_{3}$ are relatively stable and can consume $\mathrm{PbI}_{2}$ to increase the phase purity of the sample. Only at temperatures above $175{ }^{\circ} \mathrm{C}$ does $\mathrm{PbI}_{2}$ formation outcompete perovskite growth, as the sublimation temperature of organic material has been significantly exceeded $\left(\sim 145{ }^{\circ} \mathrm{C}\right.$ for formamidinium iodide ${ }^{89}$ ).

\section{G. Degradation studies}

Alongside in situ structural studies of perovskite formation, scattering techniques have also been applied to understand the kinetics and mechanisms of perovskite degradation. The effects of high temperatures on material sublimation have already been discussed in this review article. For moisture, its effects have so far been considered in the context of perovskite formation. Under the most stressful conditions, exposing pre-made $\mathrm{CH}_{3} \mathrm{NH}_{3} \mathrm{PbI}_{3}$ to condensed water will result in its irreversible breakdown into methylamine and lead iodide, with hydroiodic acid as an additional by-product. ${ }^{51,90}$ The relatively lower solubility of lead iodide in water results in its increased concentration in the degraded film, thereby increasing the likelihood of it being detected in XRD measurements. For example, Yang et al. identified $\mathrm{PbI}_{6}{ }^{4-}$ in $\mathrm{CH}_{3} \mathrm{NH}_{3} \mathrm{PbI}_{3}$ films exposed to high relative humidity $(>80 \%)$ for several hours and hypothesized that such a phase mediates the early stages of film decomposition. ${ }^{90}$ As an alternative, exposing the same perovskite to water vapor delays the onset of irreversible material breakdown. Here, degradation evolves via a transitional phase where the semiconductor is partially hydrated and may return back to $\mathrm{CH}_{3} \mathrm{NH}_{3} \mathrm{PbI}_{3}$ by extended drying. Figure 14 provides insight into this process, where in situ XRD data are presented for both the hydrating and dehydrating steps. Through combined X-ray and spectroscopic ellipsometry measurements on unencapsulated $\mathrm{CH}_{3} \mathrm{NH}_{3} \mathrm{PbI}_{3}$ films, Leguy et al. demonstrated that water molecules hydrate the perovskite over several minutes, suggesting that crystal grain boundaries play an important role in their ability to ingress the film. In a manner that is analogous to the infiltration of $\mathrm{CH}_{3} \mathrm{NH}_{3} \mathrm{I}$ into $\mathrm{PbI}_{2}$ during "two-step" perovskite formation, water molecules swell the film and hydrate individual grains from their exterior inwards, partially disrupting their orientation in the process. For working solar cells, these 'monohydrate' phases (i.e., $\mathrm{CH}_{3} \mathrm{NH}_{3} \mathrm{PbI}_{3} \cdot \mathrm{H}_{2} \mathrm{O}$ ) act as insulating barriers between unreacted perovskite domains, resulting in substantially reduced charge transport and extraction efficiencies. Although dehydration of the monohydrate phase can result in the full recovery of the original perovskite composition, its optoelectronic properties will remain altered, supporting the notion of a recrystallized perovskite morphology. Extended moisture exposure induces full conversion of the perovskite into a hydrated phase before undergoing decomposition, where excess water facilitates the dissolution of methylammonium.

In situ degradation studies for perovskite semiconductors are at an earlier stage of development compared to processing studies; however they are likely to grow in popularity to provide insight into the intrinsic stabilities of different perovskite compositions and dimensionalities. Stability issues that are currently poorly understood are the decomposition-induced effects of UV light and oxygen, ${ }^{91-93}$ either synergistically or as individual stress 

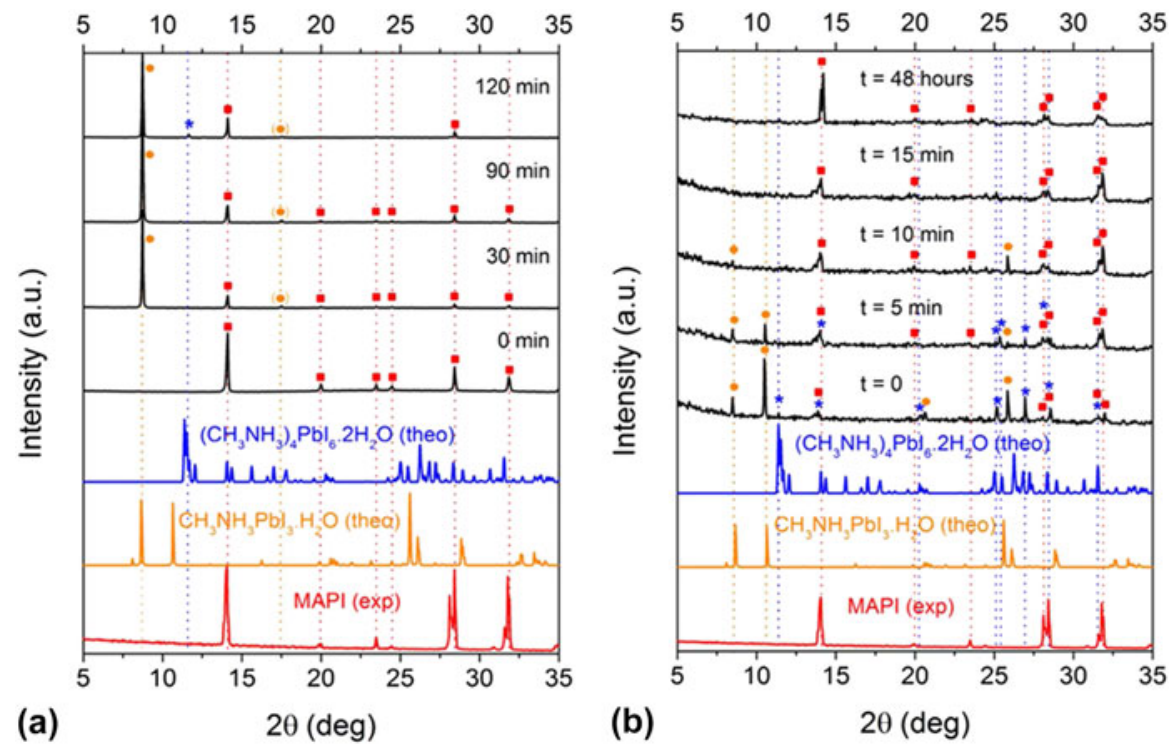

FIG. 14. In situ XRD patterns for a $\mathrm{CH}_{3} \mathrm{NH}_{3} \mathrm{PbI}_{3}$ film exposed to humid air (80\% relative humidity) (a) and a subsequent drying step (35\% relative humidity) (b). Reprinted with permission from Ref. 51. Copyright 2015 American Chemical Society.

factors. For oxygen, interaction between methylammonium lead iodide, oxygen, and a free electron results in the perovskite breaking down into methylamine and lead iodide, with iodine and water as additional by-products. ${ }^{87}$ Initial studies have provided strong evidence for this process being as severe, if not more so, than the effects of moisture on the properties of the semiconductors, however the role of intermediate/non-perovskite phases remains unknown.

\section{IN SITU MORPHOLOGY CHARACTERIZATION FOR ORGANIC PV FILMS}

A major theme within solution processable organic photovoltaics (OPVs) research is the study of active layer nanostructure or morphology. ${ }^{8,14,94-96}$ As the primary photoexcited state in organic semiconductors is a singlet exciton with a typical binding energy of $\sim 0.3 \mathrm{eV},{ }^{97}$ a key requirement for efficient photocurrent generation in these devices is the semiconductor bulk-heterojunction (BHJ), where differences in electron affinity and molecular aggregation between an electron donor and electron acceptor provide a driving force for charge separation. ${ }^{98-102}$ Because of the short $(\sim$ several $\mathrm{nm})$ diffusion length of singlet excitons, ${ }^{97,103,104}$ the characteristic lengthscale within $\mathrm{BHJ}$ semiconductor blends is commensurate with this distance to ensure that the efficiency of exciton dissociation is maximized. From a structural standpoint, therefore, achieving high overall PCE in an OPV requires careful designing of the light harvesting layer nanostructure, such that the bulk interfacial area between the electron donor and electron acceptor is balanced with the volume and connectivity of the pure semiconductor material that facilitates efficient charge transport and extraction. Factors that significantly affect the morphology of OPV thin films processed from solution include the chemical structures of the molecular semiconductors, their relative mixing ratio, the composition of the casting solvent, the dynamics of film formation, and the use of postcasting annealing treatments.

\section{A. Structure formation during solution processing}

The donor:acceptor blend poly(3-hexylthiophene): $[6,6]$-phenyl $\mathrm{C}_{61}$-butyric acid methyl ester (P3HT: PCBM) has long acted as a reference system for constructing structure-property relationships in OPV research. ${ }^{96,105}$ During solution casting, structure formation in this semi-crystalline blend proceeds via material crystallization and aggregation, processes that are triggered by the solid content of the drying film exceeding certain thresholds. Through in situ GIWAXS measurements on bar-coated thin films, Wang et al. identified a critical solid concentration of 50\% in 1:0.8 wt\% P3HT: PCBM blends, beyond which the rate of P3HT lamella stacking increased significantly. ${ }^{106}$ Using spectroscopic ellipsometry, this behavior was correlated with the rapid increase in the film extinction coefficient and absorption red-shift, changes that are consistent with the planarization and extended effective conjugation length of P3HT chains. By casting the film at relatively low temperatures or by using a low-volatility/high boiling point solvent, the absolute crystallinity of the sample was enhanced through an extended crystallization time. A closely related GIWAXS study by Schmidt-Hansberg et al. identified a lower solid concentration for the onset of weak lamella ordering of $\mathrm{P} 3 \mathrm{HT}-14 \%$ for the same blend composition—alongside 
a threshold concentration for PCBM aggregation (50\%). ${ }^{107}$ The evolution in the film texture during drying, where P3HT chains initially aligned edge-on to the substrate before adopting a wider orientation distribution, highlighted the role of the buried interface in defining the film nanostructure and reaffirmed the vertically heterogeneous character of these blend thin films. From these results, a multi-stage description of blend structure formation was proposed, where P3HT crystallization drives PCBM molecules into amorphous regions of the wet film, increasing their local concentration. In parallel with continued solvent evaporation, this process proceeds until fullerene ordering is triggered; however the presence of P3HT crystallites restricts their growth and as a consequence only nanoscale aggregations can form (Fig. 15). When the fullerene loading is sufficiently high however, and the polymer is relatively amorphous, the stages of film formation can be reversed. Time-resolved measurements on 1:4 wt $\%$ poly $\left[N-9^{\prime}\right.$-heptadecanyl-2,7-carbazole-alt-5,5-(4', $7^{\prime}$-di -2-thienyl-2', 1', $3^{\prime}$-benzothiadiazole)] (PCDTBT):
PCBM blends cast from dichlorobenzene have shown that whilst PCBM aggregation occurs once its solubility limit in the drying film has been reached $(\sim 4 \%$ solid concentration), short-range ordering of the polymer only takes place in the final stage of the drying process $\left(>75 \%\right.$ solid concentration). ${ }^{108}$

\section{B. The role of co-solvents and solvent additives}

In semi-crystalline diketopyrrolopyrrole (DPP):PCBM blends cast from chloroform/dichlorobenzene (CF/DCB) solvent mixtures, a similar sequence of structure formation to P3HT:PCBM blends has been identified. ${ }^{109}$ Mechanistically, the as-cast morphology of this blend results from mixing a low volatility solvent that affords good solubility for the fullerene component (DCB) with a highly volatile solvent that provides greater solubility for the polymer (CF). During solution casting, fast evaporation of the 'good' polymer solvent in the film worsens the overall quality of any remaining solvent and encourages polymer aggregation and crystallization. Extended
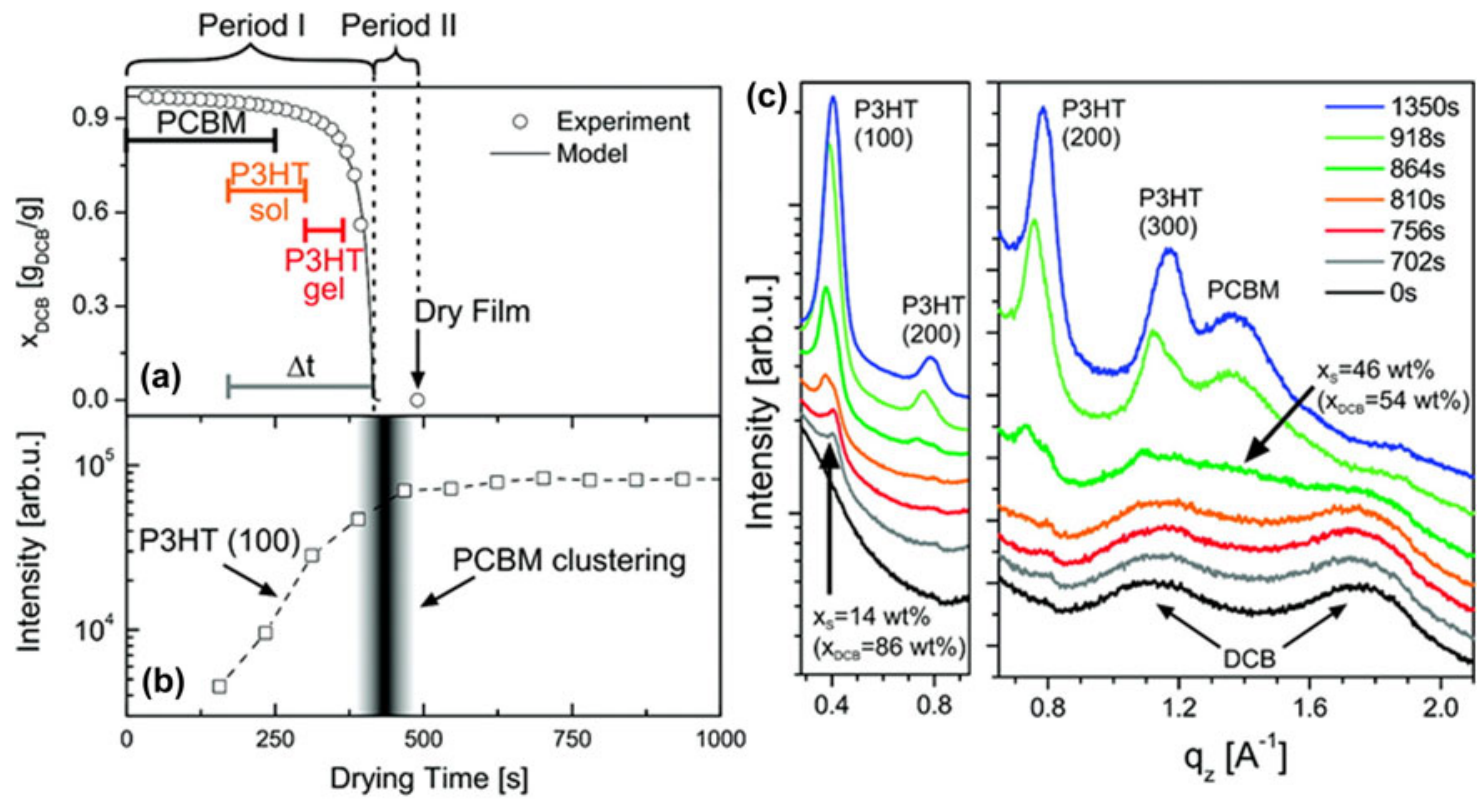

(d)
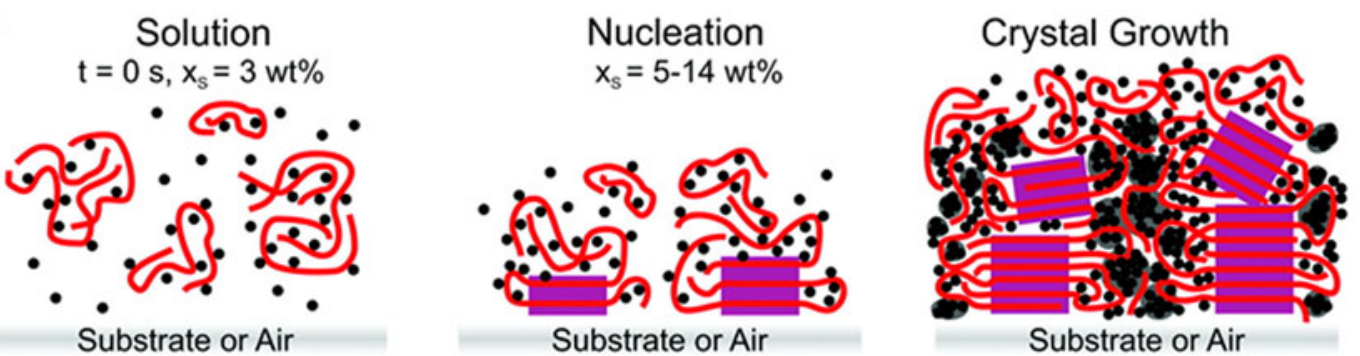

FIG. 15. Evolution in P3HT:PCBM film morphology during solution casting. Part (a) depicts the evolution in film solid concentration as a function of drying time, as determined from in situ optical reflectivity measurements. The growth kinetics of P3HT crystallization-inferred from the integrated intensity of the (100) X-ray reflection that corresponds to polymer lamella ordering-are shown in (b). Out-of-plane GIWAXS patterns at key points in the drying process are shown in part (c). These datasets are used to construct a model for film formation, which is illustrated schematically in part (d). Reprinted with permission from Ref. 107. Copyright 2015 American Chemical Society. 
evaporation of the remaining solvent eventually triggers fullerene aggregation within the partially formed semicrystalline polymer matrix. Adjusting the CF-to-DCB solvent ratio in favor of either component influences the film drying kinetics as well as the sizes and purities of polymer- and fullerene-rich domains, as the data presented in Fig. 16 show. Here, the in situ X-ray scattering measurements were made on slot-die coated blends of diketopyrrolopyrrole-quaterthiophene

(DPPBT): $\mathrm{PC}_{71} \mathrm{BM} .{ }^{110}$ It is interesting to note that for the case for $5 \mathrm{vol} \%$ DCB in the casting solution, phase separation of the fullerene precedes lamella crystallization of the polymer (inferred from the intensity of X-ray scatter from the (100) plane), a process that is likely due to the rapid loss of solvent from the film. Furthermore, as the data for the $50 \mathrm{vol} \%$ DCB sample show, the crystallinity of the polymer can be enhanced either through changes in the casting solvent composition or film drying time, neatly highlighting the complexity of morphology optimization in polymer:fullerene blend systems.

Under optimized conditions, the delayed aggregation of PCBM (alternatively the preferred crystallization of the DPP copolymer) during solution casting promotes the growth of a phase separated morphology with a characteristic lengthscale and phase purity that enable efficient PV behavior, obviating the need for further processing steps such as thermal annealing. As shown in Fig. 17, combined optical interference, scattering, and absorption measurements have suggested that a solid concentration of $20 \%$ in drying DPP:PCBM blend films sets the threshold for fullerene aggregation via liquid-liquid phase separation, ${ }^{111}$ and that large scale polymer:fullerene phase separation can only be prevented by triggering polymer aggregation in solution before this point.

The generality of this behavior can be appreciated when considering other studies and reviews on co-solvent and additive processed OPV blends. ${ }^{111-113}$ High boiling point additives such as octanedithiol (ODT) and DIO exhibit good solubility of PCBM. ${ }^{113}$ When used in small vol\% with standard processing solvents such as chlorobenzene, the deposition of co-polymer-PCBM blends prioritizes aggregation and ordering of the polymer phase over the potentially large scale phase separation of PCBM. ${ }^{114}$ In addition, the time required for the film to completely dry is significantly extended because of the additives' low volatility. This means that during the final stages of film formation (corresponding to solid concentrations exceeding 80 or $90 \%$ ), domain coarsening can still take place as residual amounts of additive become trapped within the sample. ${ }^{115}$

A general description of additive-controlled BHJ formation was provided by Richter et al., ${ }^{116}$ who studied blade-coated P3HT:PCBM blends prepared using ODT or 1-chloronaphthalene $(\mathrm{CN})$ in the casting solvent (Fig. 18). When no additive is present, the growth of
P3HT crystallites is frustrated by (i) the presence of PCBM and (ii) a high glass transition temperature $\left(T_{\mathrm{g}}\right)$ of the blend relative to the casting temperature $\left(\sim 50{ }^{\circ} \mathrm{C}^{117}\right.$ versus $\left.40{ }^{\circ} \mathrm{C}\right)$. When $\mathrm{CN}$ additive is present, P3HT undergoes prolonged crystallization after the primary solvent has evaporated from the film, facilitated by a CN-plasticized mixed amorphous phase with low $T_{\mathrm{g}}$. In contrast, ODT initiates the formation of two liquid/ amorphous phases that are rich in PCBM and P3HT, respectively. The selective dissolution of PCBM into ODT (i.e., a liquid phase) provides the basis for a P3HTrich phase, again lowering $T_{\mathrm{g}}$. Importantly, only the ODT process requires the additive to selectively dissolve PCBM, its poor solubility for P3HT allows the creation of a second liquid phase which separates the two semiconductors.

In contrast to any of these processes, thermal annealing of an as-cast film (or a polymer:fullerene bilayer sample) does not afford the same level of morphology control because the aggregation and/or crystallization of one material takes place in parallel with (and may consequently be limited by) the thermally activated diffusion of the second material. ${ }^{114,118}$ Alongside a reduced thermal budget, it is the ability to optimize the donor, acceptor, and mixed phases in sequence that has led to solvent engineering becoming a popular strategy for OPV optimization.

The studies reviewed so far have provided an improved understanding of the common dynamics of film formation in OPV blends; however they rarely directly replicate the conditions used in the preparation of highefficiency OPVs. In general, these devices are prepared via spin-coating of the semi-conductor blend ink, and as a consequence measurements are required with much higher time resolution to accurately monitor the film as its structure and composition evolves. Using fast (100 ms/ frame) GIWAXS/GISAXS measurements, this challenge was overcome by Amassian and co-workers who characterized the spin-coating process for blends of P3HT: PCBM, as shown in Fig. 19. ${ }^{119}$ For device optimized P3HT:PCBM blend compositions, polymer crystallization and fullerene phase separation were measured to occur in parallel within the first second of spin-coating, corresponding to a film solid concentration of a few $\%$. Such structures were determined to be relatively stable in size and population until a film sold concentration of $\sim 17 \%$ was reached, after which time a rapid increase took place. Modifying the semiconductor blend solution toward P3HT- or PCBM-rich compositions favored the formation of larger polymer and fullerene domains, respectively, in the formed film, in addition to reducing the volume fraction of mixed-phase material. Here, it is important to recognize that the morphology of rapidly cast P3HT:PCBM does not enable favorable PV behavior, and that thermal and/or solvent annealing treatments are necessary to realize high PCEs. ${ }^{94,96}$ 

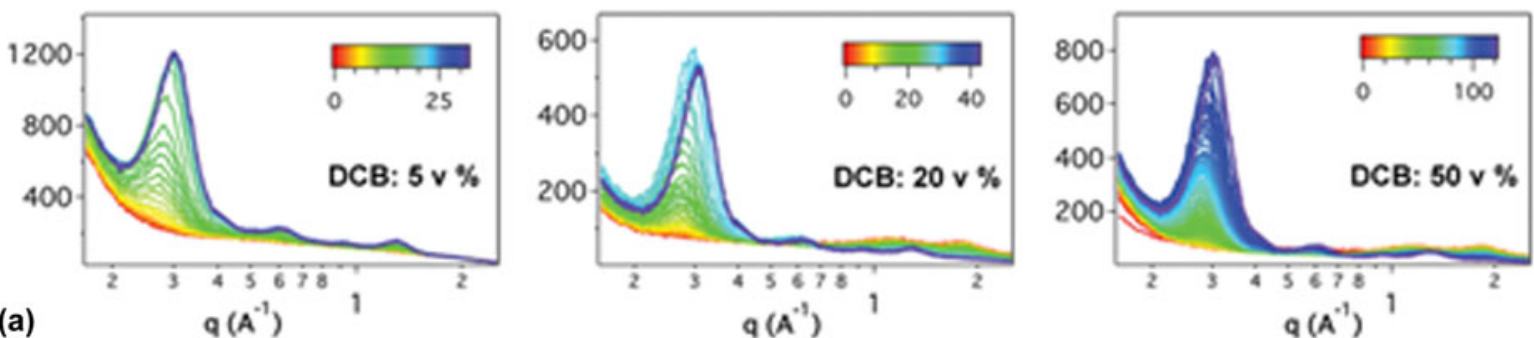

(a)

$q\left(A^{-1}\right)$

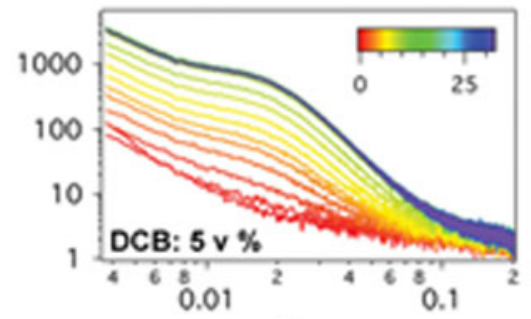

(b)

$q\left(A^{-1}\right)$

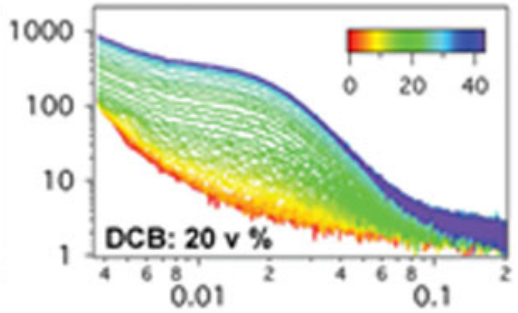

$q\left(A^{-1}\right)$

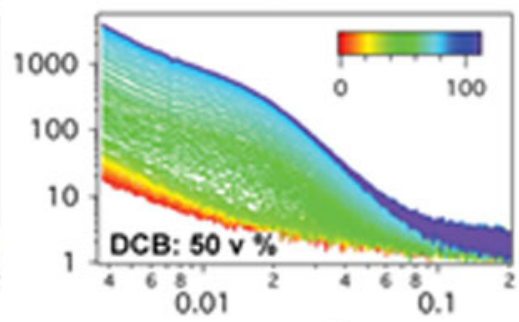

$q\left(A^{-1}\right)$
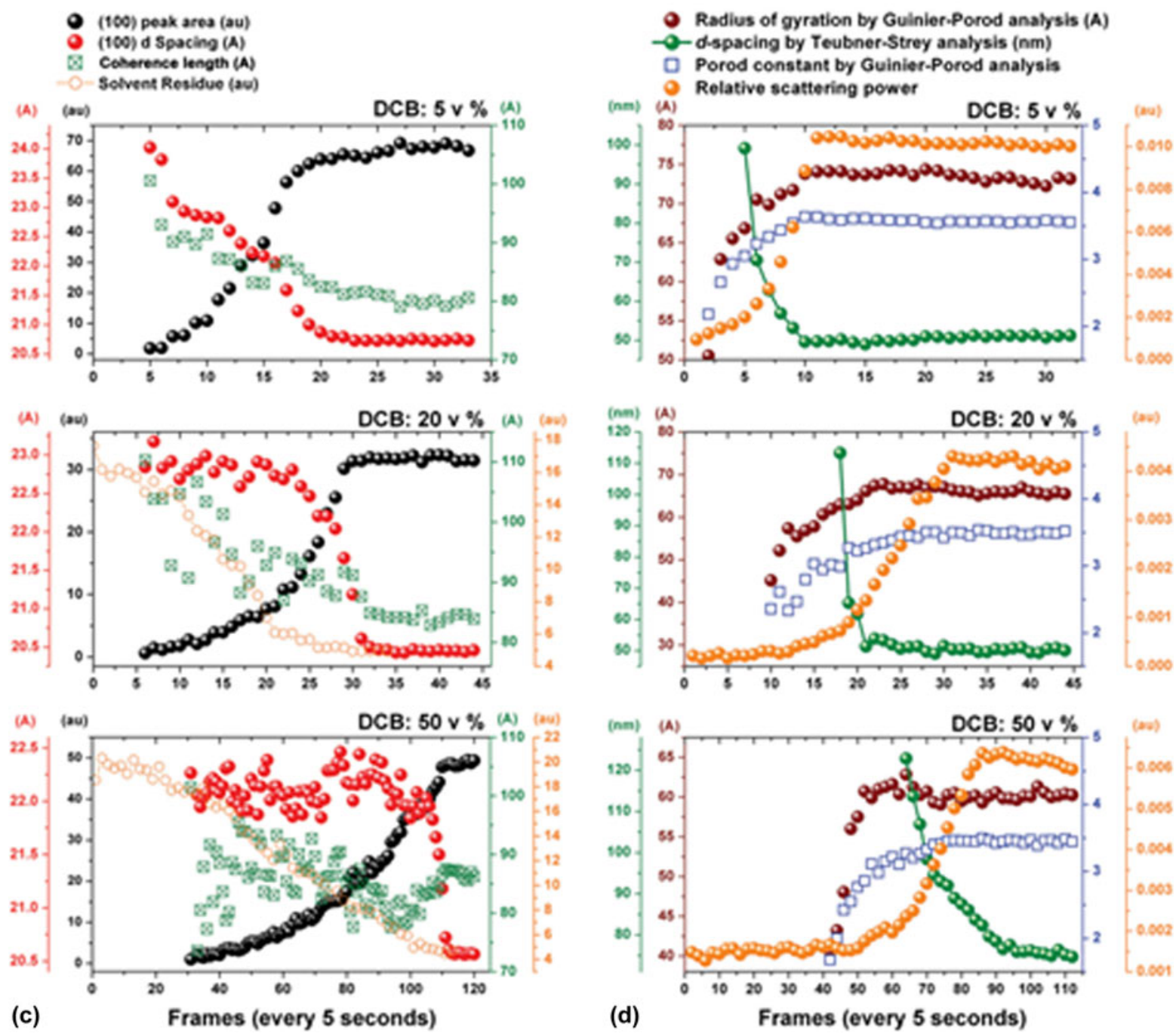

FIG. 16. Evolution in film morphology for blends of DPPBT:PC ${ }_{71} \mathrm{BM}$ cast from chloroform/dichlorobenzene solvent mixtures, as characterized by in situ GIWAXS (a) and GISAXS (b). Here the GIWAXS measurements are used to characterize the crystallization of the polymer and the loss of solvent residue forms the film, and the GISAXS measurements are used to probe the characteristic domain size of phase separated aggregates. Detailed kinetic analyses on both datasets are presented in parts (c) and (d), respectively. Figure reprinted with permission from Ref. 110. Copyright 2015 Wiley-VCH. 

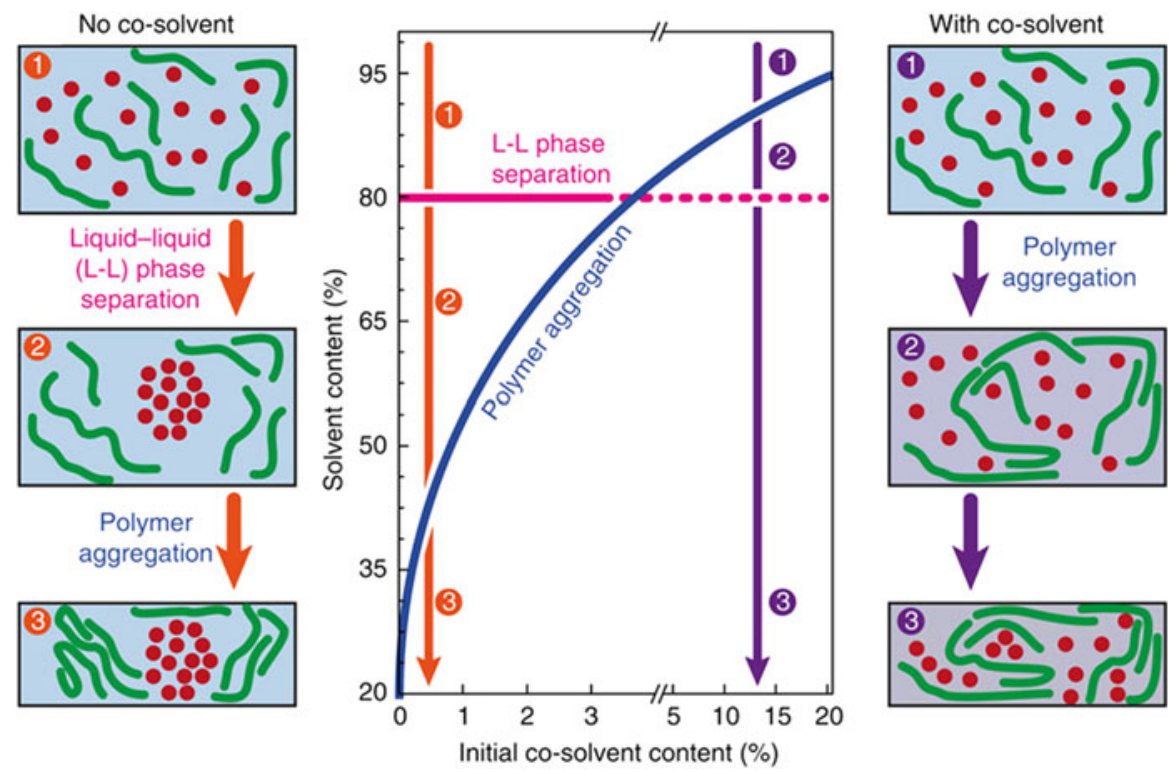

FIG. 17. Phase diagram highlighting the conditions for polymer aggregation in DPP:fullerene blends prepared with varying concentrations of cosolvent in the casting solution. Accompanying figures illustrate schematically the key steps in structure formation with or without co-solvent processing. Reprinted with permission from Ref. 111. Copyright 2015 Nature Publishing Group.

A follow-up study on spin-coated blends prepared using $\mathrm{CB} / \mathrm{DIO}$ confirmed that many of the mechanisms of structure formation for polymer:fullerene systems are also applicable to small molecule:fullerene systems. ${ }^{120}$ Here, the emergence of novel and efficient small molecule electron donors-promoted as a route to achieving reproducible semiconductor batches at a relatively low cost -has motivated the study of structure formation in these systems to provide a point of comparison to polymeric blends. For 7,7'-(4,4-bis(2-ethylhexyl)- $4 H$-silolo[3,2$\left.b: 4,5-b^{\prime}\right]$ dithiophene-2,6-diyl)bis(6-fluoro-4-(5'-hexyl[2,2'-bithiophen]-5-yl)benzo[c][1,2,5] thiadiazole) $\left(p\right.$-DTS $\left.\left(\mathrm{FBTTh}_{2}\right)_{2}\right): \mathrm{PC}_{71} \mathrm{BM}$ blends, a metastable $p$-DTS $\left(\mathrm{FBTTh}_{2}\right)_{2}$ polymorph was identified during the first few seconds of spin-coating, which was proposed to influence the final film morphology. As with other studies on the use of DIO, its low volatility results in residual amounts remaining in the blend film, prolonging its drying time and promoting enhanced crystallization of the solid components. A factor that cannot be overlooked for this BHJ system however is that DIO is a relatively good solvent for $p$-DTS $\left(\mathrm{FBTTh}_{2}\right)_{2}{ }^{121}$ Accordingly, aggregation and crystallization of the small molecule are delayed from the solution phase to the final stages of film drying, with intermediate vitrification of the amorphous material taking place directly rather than indirectly through the preferred solvation of $\mathrm{PC}_{71} \mathrm{BM}$ out of the mixed phase, as is often seen in polymer:fullerene blends. The direct or indirect plasticization of semiconductor material in BHJ systems during film therefore results in two distinct pathways of morphology formation (see the discussion of P3HT:PCBM blends prepared using
$\mathrm{CN}$ or DIO), with the favored route depending upon the solvent quality of the additive relative to the electron donor material.

\section{Up-scaling of promising OPV systems}

The different formation kinetics and final morphologies between spin-coated and bar- or blade-coated OPV films provide some insight into why a solar cell performance gap exists between each processing method. Specifically, champion OPVs are more likely to be demonstrated using spin-coating because of the ease with which uniform films can be realized over small $\left(\sim 1 \mathrm{~cm}^{2}\right)$ substrates. As with the commercialization of perovskite $\mathrm{PVs}$, the challenge of maintaining performance parity when moving to a scalable solution deposition method is not simply a case of maintaining layer thickness parity, as this does not necessarily replicate the relatively rapid solvent loss characteristics and kinetically trapped morphologies of spin-coating. Furthermore, a processing factor that is exclusive to BHJ organic solar cells is the tolerance of high PCE values to multiple donor:acceptor morphologies. In situ studies on current state-of-the-art OPV blends have helped to rationalize these differences and provide a framework for the informed design of semiconductor ink formulations that are optimized for a given solution deposition process.

The electron donor copolymer poly[(5,6-difluoro- $2,1,3$ benzothiadiazol-4,7-diyl)-alt-(3,3'"'-di(2-octyldodecyl)-2,2'; $5^{\prime}, 2^{\prime \prime} ; 5^{\prime \prime}, 2^{\prime \prime \prime}$-quaterthiophen-5,5"'-diyl)] (PffBT4T-2OD) has been shown to exhibit PCE values above $10 \%$ when paired with several fullerene-derivative electron acceptors. ${ }^{122}$ 


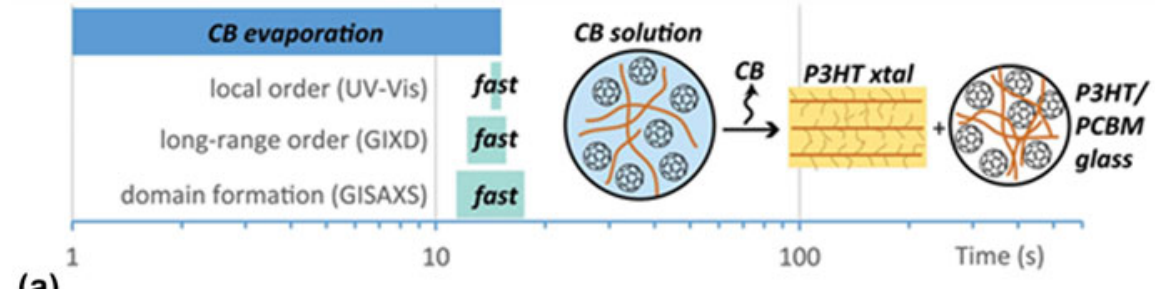

(a)

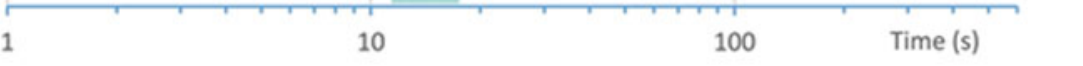
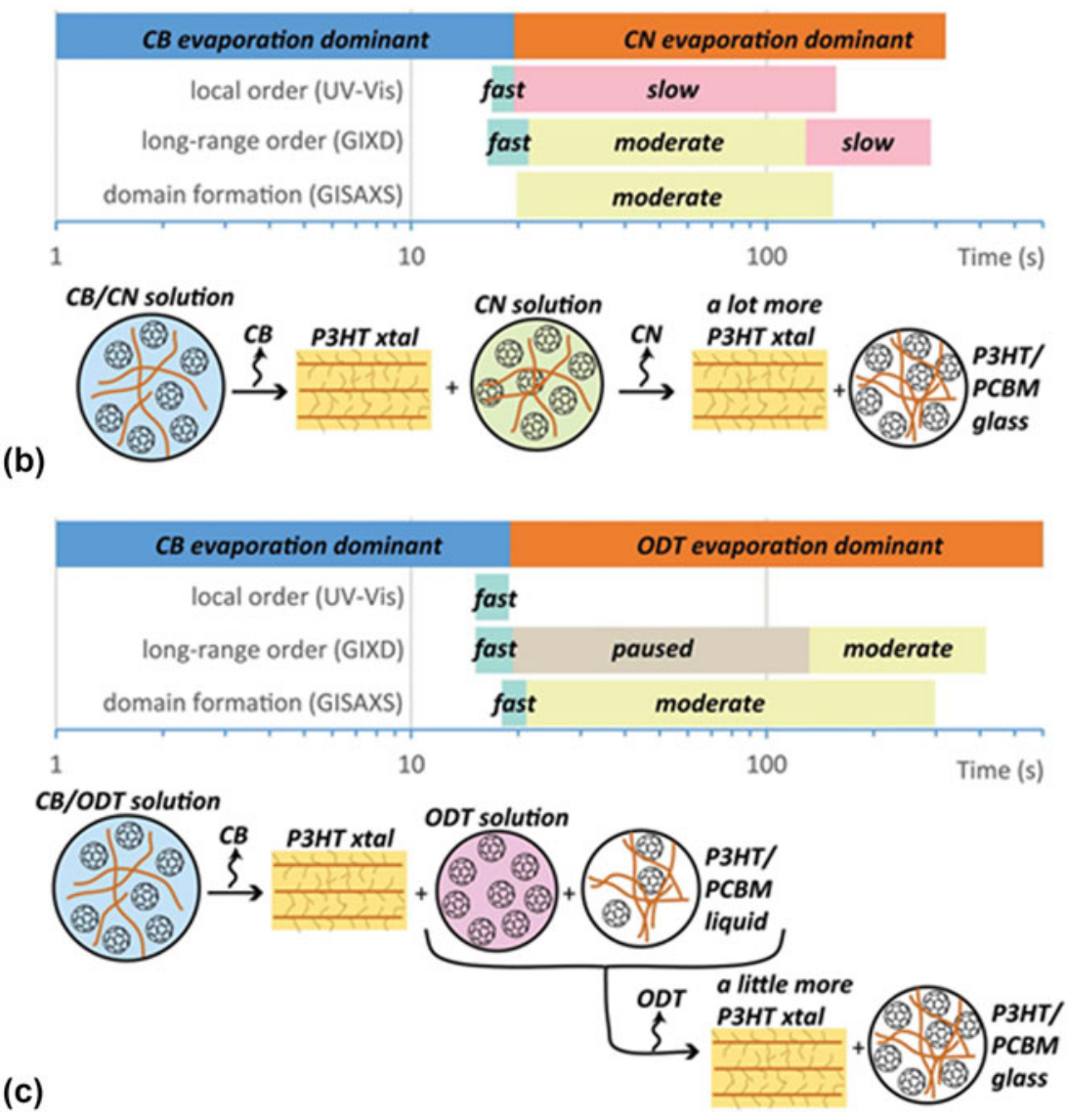

FIG. 18. Overview of film formation mechanisms and kinetics for P3HT/PCBM blends cast from (a) $\mathrm{CB}$, (b) $\mathrm{CB}$ with $\mathrm{CN}$ additive, and (c) $\mathrm{CB}$ with ODT. Figure reprinted with permission from Ref. 116. Copyright 2015 Wiley-VCH.

Because of the tendency of the copolymer to excessively aggregate in solution at ambient temperatures, blend films have to be deposited from hot $\left(\sim 90{ }^{\circ} \mathrm{C}\right)$ solutions. This approach has a clear impact on the film drying time; however when moving from spin-coating to blade-coating, differences in film morphology do not necessarily translate to differences in solar cell PCE. The work by Ro et al. has shown that optimized blade-coated PffBT4T-2OD: $\mathrm{PC}_{71} \mathrm{BM}$ films have a preferential edge-on orientation of polymer crystallites compared to face-on orientation for spin-coated films ${ }^{123}$ as well as a bimodal versus singular characteristic phase separation length-scale. These differences are partly explained by the controlled temperature history of the blade coated sample-spin-coating a hot solution is likely to result in a rapid and uncontrolled cooling process - that accelerates the onset of polymer aggregation [Fig. 20 part (a)]. The difference in polymer orientation can be understood by considering the preference and enhanced ability for dissolved PffBT4T-2OD to align edge-on with respect to the air interface, thereby minimizing its interface energy over a pre-formed aggregate. For optimized spin- and blade-coating procedures, both morphologies retained high phase purity and it was concluded that this factor was a key to realizing high PCEs, above $9 \%$ in each case.

The results clearly show that the different film formation dynamics give rise to distinct PffBT4T-2OD:PC $\mathrm{PC}_{71} \mathrm{BM}$ semiconductor layer morphologies. Although this is a fortuitous outcome in the context of identical OPV efficiencies, other polymer:fullerene blends require certain 


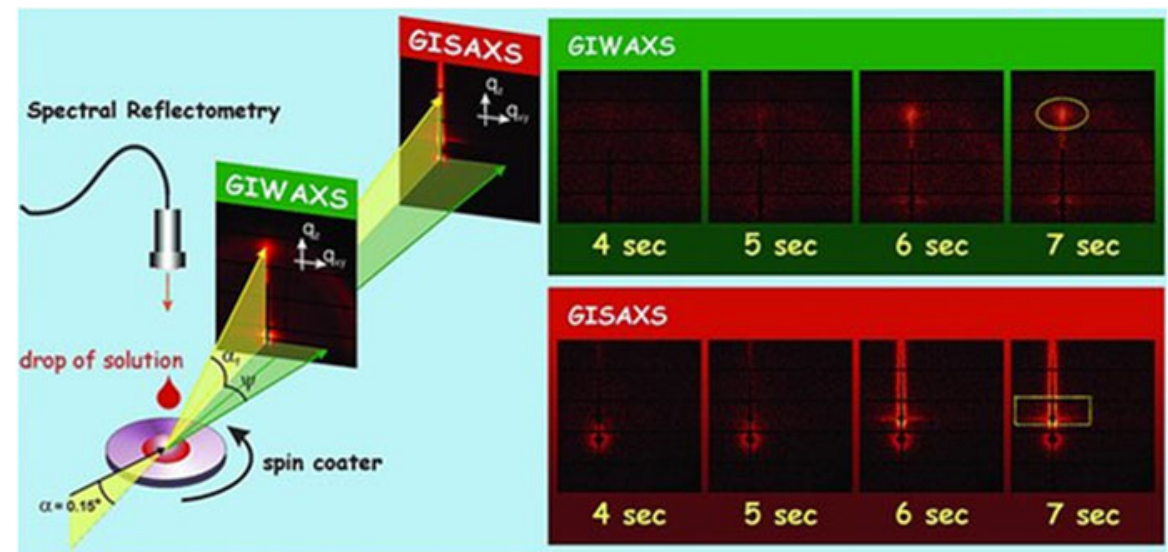

(a)
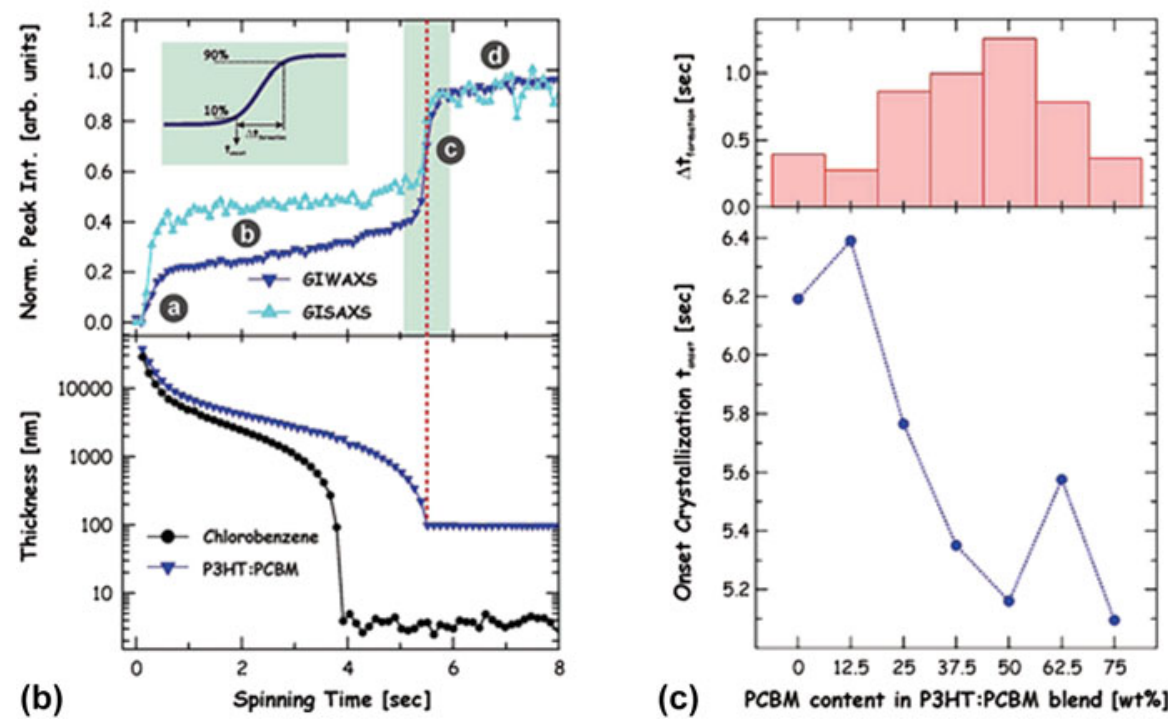

(c) PCBM content in P3HT:PCBM blend [wt\%]

FIG. 19. In situ grazing-incidence X-ray scattering measurements of P3HT:PCBM during spin coating. Part (a) illustrates the principle components of the experimental setup. In part (b), the evolution in polymer ordering (inferred from the GIWAXS signal intensity), fullerene aggregation (inferred from the GISAXS signal intensity), and the thickness of the drying film are compared. Part (c) compares the time for morphology formation with the onset time for material crystallization, as a function of P3HT:PCBM blend composition. Figure reprinted with permission from Ref. 119. Copyright 2013 Wiley-VCH.

modifications to the casting semiconductor ink to achieve performance parity. Mixtures of poly[[4,8-bis[(2ethylhexyl)oxy]benzo[1,2-b:4,5- $\left.b^{\prime}\right]$ dithiophene-2,6-diyl][3 -fluoro-2-[(2-ethylhexyl)carbonyl]thieno[3,4- $b]$ thiophenediyl]] (PTB7): $\mathrm{PC}_{71} \mathrm{BM}$ fall into the category of OPV blends that are primarily optimized using solvent/solvent additive ink formulations, the mechanistic benefits of this approach have been discussed earlier. Here, however, the direct use of an ink formulation that is optimized for spin-coating does not afford good device efficiencies using blade-coating because of the excessively delayed onset of the additive-dominated evaporation regime in the latter, resulting in a BHJ morphology that is too finely mixed. ${ }^{124}$ Whilst decreasing the concentration of the semiconductor blend ink for blade-casting provides a straightforward means to achieve thickness parity when all other processing parameters (such as substrate temperature, blade speed, and angle) are kept constant, correcting for differences in the additive-solute volume ratio is critical to replicating the nanostructures present in spin-coated films. For blends of PTB7:PC ${ }_{71} \mathrm{BM}$ and other high performance copolymer:fullerene pairings, Zhao et al. have shown that how performance parity in blade-coated layers was reached by increasing the DIO concentration from 3 vol\% up to $6-9$ vol\%. The maximum efficiency obtained in this study for bladecoated solar cells-9.7\%-is the highest for OPVs prepared using this deposition technique, confirming the benefits of their approach.

\section{Structure evolution during film thermal and solvent annealing}

Thermal and solvent annealing, as strategies for improving the efficiency of OPVs, have dropped in 

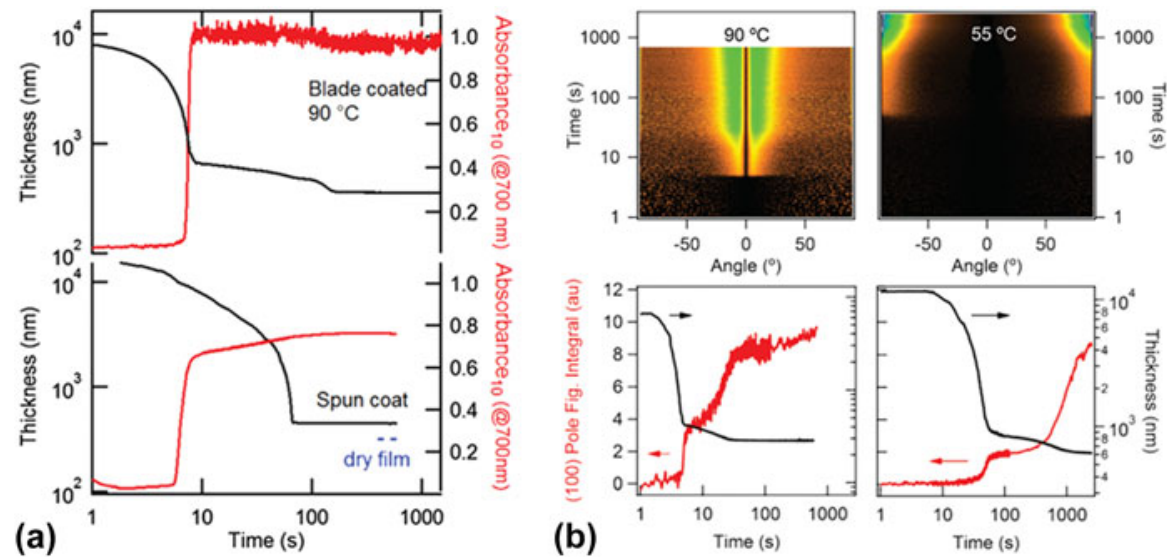

(b)

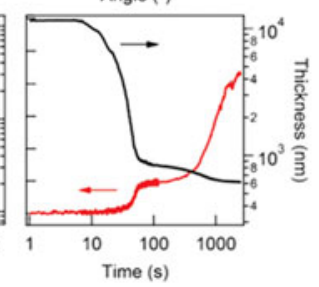

FIG. 20. (a) Comparison of film drying dynamics for PffBT4T-2OD:PC ${ }_{71} \mathrm{BM}$ blends prepared using CB/DIO solvent mixtures. Here, sample absorbance at $700 \mathrm{~nm}$ is used as a measure of PffBT4T-2OD aggregation. The data show that during blade coating the polymer undergoes aggregation at a higher film solid concentration (smaller thickness) than for spin-coated samples. Part (b) compares the differences in polymer lamella ordering and crystallite orientation during blade coating at $90{ }^{\circ} \mathrm{C}$ or $55{ }^{\circ} \mathrm{C}$, where the lower temperature corresponds to a regime where polymer pre-aggregation in solution is favored. Note that the in situ GIWAXS figures are presented using a pole figure notation that clearly highlights variations in crystal orientation. Here an angle of $0^{\circ}$ corresponds to the out-of-plane direction. ${ }^{123}$ Reproduced by permission of The Royal Society of Chemistry.

popularity since the growth of additive processing and solvent engineering. In general, subjecting a blend thinfilm to either annealing treatment ripens the degree of phase separation between the constituent semiconductors, resulting in enhanced crystallization and aggregation as well as a modified phase composition (i.e., the volume fractions of pure and mixed material). When two different semiconductors are interfaced in a simple bilayer geometry, annealing can be used to activate intermixing; the information obtained from such experiments is highly valuable for determining semiconductor diffusion rates and equilibrium mixed-phase compositions. ${ }^{114,125}$ For thermal annealing, these processes are activated when the temperature of the film exceeds certain values; for example, $T_{\mathrm{g}}$ of the polymer or the onset temperature for small molecule crystallization. Thermal annealing also facilitates the loss of trapped solvent within the film, either at its boiling point or at temperatures exceeding $T_{\mathrm{g}}{ }^{126}$ In contrast, semiconductor phase separation and restructuring via solvent annealing are achieved by exposing the materials to a solvent vapor. Under these conditions, a semiconductor thin film swells due to the partial dissolution of solid material, resulting in enhanced chain and molecular mobilities. In a manner that is similar to the use of co-solvent deposition, solvent annealing in vapor that is orthogonal/of poor solubility to one blend component permits the sequential restructuring of the film; however the impact of this step is limited by the processing history of the sample, in particular the structures already formed during film casting.

For BHJ polymer:fullerene blends, the factors identified from in situ annealing measurements that are relevant to the growth modes and kinetics of polymer crystallites and fullerene aggregates have been recently reviewed elsewhere. ${ }^{7}$ For small molecule:fullerene blends, Sharenko et al. combined in situ GIWAXS/GISAXS to study thin films of DPP(TBFu $)_{2}: \mathrm{PC}_{71} \mathrm{BM}$ as well as films of neat $\mathrm{DPP}(\mathrm{TBFu})_{2}$ during a thermal anneal. ${ }^{127}$ Across a broad composition range of 30-70 wt $\%$ fullerene loading, DPP(TBFu $)_{2}$ crystallization was found to be the dominant driving force for phase separation in the blend, which facilitated improved charge carrier mobilities and overall solar cell efficiencies. By driving fullerene molecules into the mixed phase of the blend, this crystallization step resulted in enriched electron donor and electron acceptor domains in the film; this process being analogous to the evolution in morphology in polymer rich $\mathrm{P} 3 \mathrm{HT}: \mathrm{PCBM}$ blends during solution casting and thermal annealing. The observed increase in the cold-crystallization temperature of $\mathrm{DPP}(\mathrm{TBFu})_{2}$ with increasing $\mathrm{PC}_{71} \mathrm{BM}$ concentration-from $50{ }^{\circ} \mathrm{C}$ to $100{ }^{\circ} \mathrm{C}$-was ascribed to a DPP $(\mathrm{TBFu})_{2}$ dilution effect that results in a reduced density of crystal nucleation sites.

Morphology evolution in small molecule:fullerene blends during solvent vapor annealing was investigated by Engmann et al. ${ }^{128}$ Here, thin films of benzodithiophene terthiophene rhodamine (BTR): $\mathrm{PC}_{71} \mathrm{BM}$ were subjected to brief $(<1 \mathrm{~min}$ ) periods of exposure to either $\mathrm{CF}$ or tetrahydrofuran (THF) vapors alongside a $110^{\circ} \mathrm{C}$ thermal anneal (Fig. 21). Whilst CF is a good solvent for both semiconductors, THF is a poor solvent for PCBM. ${ }^{129}$ As a consequence, CF solvent annealing drives enhanced phase separation over THF annealing by efficiently dissolving amorphous material and relatively small crystallites. The limited ability of THF to 
dissolve small crystallites maintained a high density of nucleation sites within the blend, resulting in a balance between enhanced crystallization, domain purity, and overall phase separation. PCEs of up to $6.5 \%$ were realized for solar cells prepared via the TFH annealing route, which represented significant improvements over $\mathrm{CF}$ annealing (5.4\%) and thermal annealing routes alone $(3.4 \%)$.

\section{E. Relating film nanostructures to device evolution}

For OPVs, the initial burn-in phase of device operation is relatively pronounced compared to other forms of emerging PV. Specifically, photocurrent densities and PCEs can decrease by several \% over $10 \mathrm{~s}$ of hours of continuous simulated solar illumination. In operando structural measurements have provided some insight into
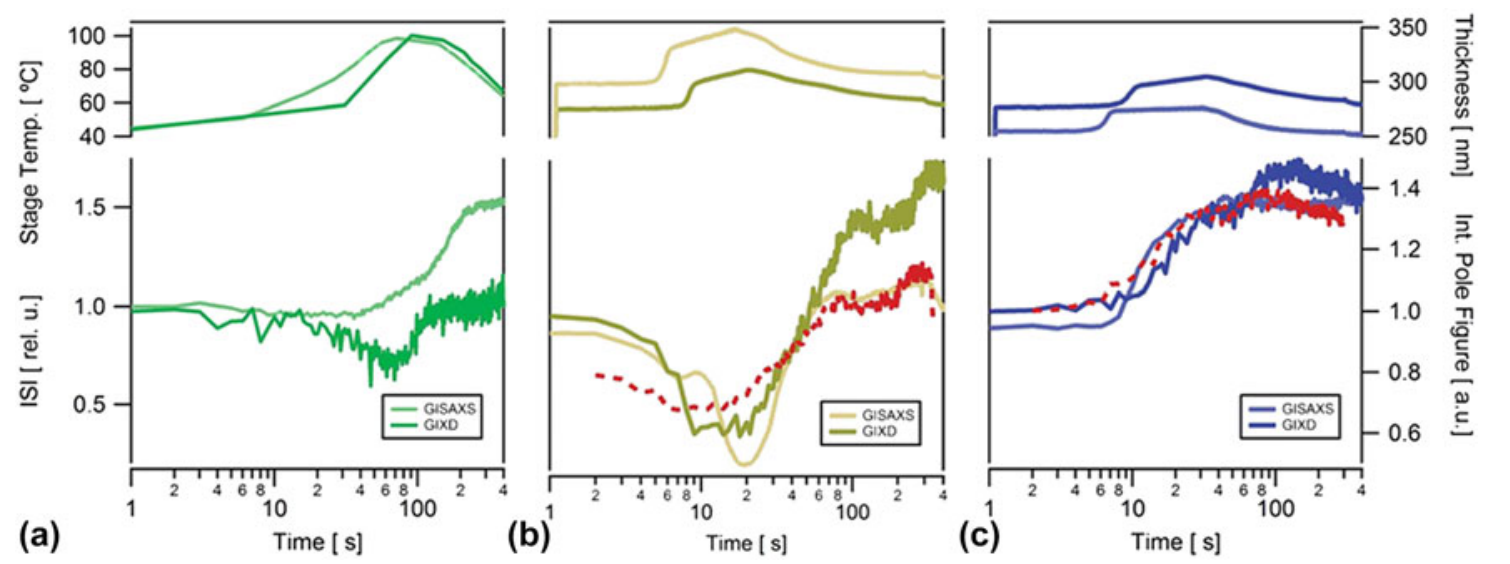

FIG. 21. In situ structural characterization data for thin film small molecule blends of BTR:PC ${ }_{71} \mathrm{BM}$ during annealing. The presented data show the evolution in GISAXS integrated scattering intensity (ISI) - sensitive to domain purity — and GIXRD integrated pole figure intensitya probe of domain crystallinity_during thermal annealing (a), combined thermal/solvent annealing (CF for the first $15 \mathrm{~s}$ ) (b) and combined thermal/solvent annealing (THF for the first $30 \mathrm{~s}$ ) (c). Red lines correspond to fits of the GISAXS data using a two phase model consisting of pure BTR and a three-component mixed-amorphous phase of BTR, $\mathrm{PC}_{71} \mathrm{BM}$, and solvent vapor. ${ }^{128}$ Reproduced by permission of The Royal Society of Chemistry.

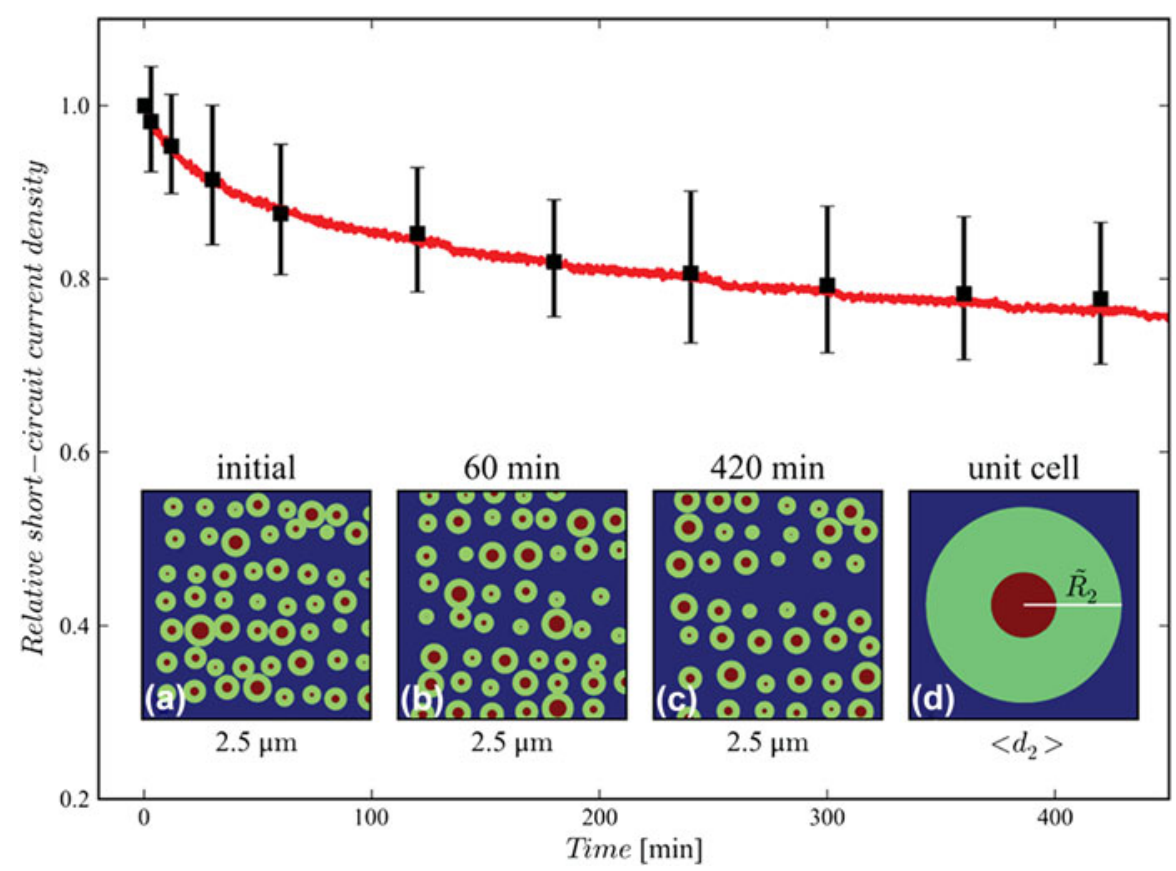

FIG. 22. Comparison of measured (red line) and modeled (black squares) photocurrent values for a P3HT:PCBM OPV during burn-in. Parts (a)-(c) schematically illustrate the P3HT:PCBM blend nanostructure at different times, as determined through in situ $\mu$-GISAXS measurements. In these figures, the red and green regions correspond to pure and mixed semiconductor phases of the dominant light absorber, respectively, where photons absorbed in these regions may be converted into free charge carriers (d). Figure reprinted with permission from Ref. 130. Copyright 2013 Wiley-VCH. 
this effect by probing a region of a device substrate that is close to, but not covered by, the metal electrode. GISAXS measurements using a focused X-ray beam ( $\mu$-GISAXS) by Buschbaum and co-workers were used to correlate reduced $J_{\mathrm{SC}}$ values in P3HT:PCBM OPVs to a reduction in the donor acceptor interfacial area within the light harvesting layer, through the amalgamation of smaller domains into larger ones. ${ }^{130}$ Here a model was constructed to predict the solar cell photocurrent based upon a domain size-dependent probability of charge generation, the output from which is presented in Fig. 22. A separate study showed the improved stability of inverted device structures relative to normal device structures; however the fundamental reason(s) for why the morphology was unstable in the first place remained unclear. $^{131}$ Given the relatively low glass transition temperature of $\mathrm{P} 3 \mathrm{HT}$, it is plausible that the amorphous phase of the blend is unstable at the operating temperature of the solar cell. ${ }^{117,132}$ For this reason, it may be the case that future in operando measurements consider the role of pre-aging treatments (e.g., light-soaking or annealing at modest temperatures ${ }^{133}$ ) in more detail, alongside the design of thermally stable semiconductor blends, as routes to realizing OPVs with greater operational lifetimes.

\section{SUMMARY \& OUTLOOK}

Time-resolved measurements of film structure and composition in situ of sample preparation have grown in popularity over the past few years to enhance our understanding of organic- and perovskite-semiconductor device processing. As key steps can now be identified in real-time of a process being carried out, research of this type is crucial for understanding how optimized semiconductor films are produced. As a consequence, the outcomes from these studies allow researchers to design new fabrication methods with greater awareness than characterizing a sample postproduction alone permits, thereby accelerating technology development and commercialization. Although perovskite and organic PV have fundamentally different modes of operation, an analysis of the recent literature from both areas highlights the importance of intermediate phases, both solid and liquid, in governing the final semiconductor film structure, as well as the sensitivity of such phases to the initial sample conditions. Given the growth in solvent engineering as the sole means of preparing high quality semiconductor films, it is likely that future studies on sample preparation will continue to investigate the interplay between different solution compositions and deposition conditions, to identify the crucial stages of film drying that must be replicated when moving to scalable manufacturing techniques. Furthermore, a subset of in situ studies have been devoted to understanding the mechanisms and kinetics of semiconductor film degradation, rather than film formation, demonstrating how these measurements can also be used to underpin research on PV stability.

\section{A. Opportunities and challenges}

The rapid pace of development in perovskite optoelectronics means that new semiconductor compositions are becoming readily available to researchers. In particular, the use of multiple A, B, and X components in state-ofthe-art perovskite films (as well as in films of lowtoxicity, as $\mathrm{Pb}$ removal would permit) raises questions about how films prepared using several precursors are formed. The role of perovskite grain orientation on sample optoelectronic properties is also only beginning to be understood, ${ }^{134,135}$ and whilst differences in crystal alignment have been resolved dynamically in some of the studies reviewed here, there is currently no proposed framework for controlling this. Lastly, in the context of advanced film formation methods, state-of-the-art solvent removal processes are becoming relatively fast (subminute), ${ }^{76,136}$ thus making it a challenge to accurately capture the important features in a time-resolved X-ray scattering measurement.

For OPVs, research into the dynamics of film formation is likely to continue to understand how BHJ nanostructures form during novel deposition methods. The use of high performance non-fullerene electron acceptors ${ }^{137}$ and ternary semiconductor mixtures in contemporary champion solar cell devices will also motivate new studies as their crystallization and aggregation behavior is likely to differ from conventional binary polymer: fullerene or small molecule:fullerene blends. As noted in the discussion on solvent engineering, the glass transition temperature of the polymer-and its relation to the substrate and solution casting temperatures-remains an important parameter in the design of optimized deposition conditions. Likewise, the role of additives as selective or non-selective solvents will be a key to understanding how they can be mimicked when OPVs undergo scale-up and commercialization.

Finally, whilst organic and perovskite PV are at different stages of technological maturity, it is important to recognize that they each face similar issues relating to the use of hazardous materials and/or solvents during their fabrication. Additional challenges relating to the intrinsic stability of the semiconductor films, long-term device stability and performance gaps between proof-ofconcept solar cells and small modules are also shared, suggesting that researchers working on either technology can learn from the in situ and in operando experiments taking place in each field. Indeed, for organic PV, a greater number of in situ studies have been carried out using scalable deposition methods (e.g., compact 
slot-die coaters and roll-to-roll processing systems that are relatively straightforward to install within an XRD or GIXRD setup) than for perovskites. Combined X-ray scattering, optical reflectivity, and absorption measurements are also at a more advanced stage of development, and by demonstrating how multiple techniques can be used to identify indirect measures of semiconductor crystallinity and nanostructure, the design of in-line tools for process monitoring can be supported.

\section{ACKNOWLEDGMENTS}

The author acknowledges support from the EPSRC through the grant EP/M024873/1 "Singlet Fission Photon Multipliers-Adding Efficiency to Silicon Solar Cells".

\section{REFERENCES}

1. R.A. Kerr: Do we have the energy for the next transition? Science 329(5993), 780 (2010).

2. A. Cho: Energy's tricky tradeoffs. Science 329(5993), 786 (2010).

3. I.E. Agency: Technology Roadmap: Solar Photovoltaic Energy (2014 Edition), (2014).

4. BP Statistical Review of World Energy 2016-Data workbook http://www.bp.com/en/global/corporate/energy-economics/ statistical-review-of-world-energy.html.

5. Global Market Outlook for Photovoltaics 2014-2018 http:// www.solarpowereurope.org/home/.

6. A. Polman, M. Knight, E.C. Garnett, B. Ehrler, and W.C. Sinke: Photovoltaic materials: Present efficiencies and future challenges. Science 352(6283), aad4424 (2016).

7. A.J. Pearson, T. Wang, and D.G. Lidzey: The role of dynamic measurements in correlating structure with optoelectronic properties in polymer:fullerene bulk-heterojunction solar cells. Rep. Prog. Phys. 76(2), 022501 (2013).

8. G. Li, R. Zhu, and Y. Yang: Polymer solar cells. Nat. Photonics 6(3), 153 (2012)

9. M.A. Green, A. Ho-Baillie, and H.J. Snaith: The emergence of perovskite solar cells. Nat. Photonics 8(7), 506 (2014).

10. S.B. Darling and F. You: The case for organic photovoltaics. RSC Adv. 3(39), 17633 (2013).

11. J. Gong, S.B. Darling, and F. You: Perovskite photovoltaics: Life-cycle assessment of energy and environmental impacts. Energy Environ. Sci. 8(7), 1953 (2015).

12. Best Research-Cell Efficiencies http://www.nrel.gov/ncpv/ images/efficiency_chart.jpg.

13. P. Müller-Buschbaum: The active layer morphology of organic solar cells probed with grazing incidence scattering techniques. Adv. Mater. 26(46), 7692 (2014).

14. W. Chen, M.P. Nikiforov, and S.B. Darling: Morphology characterization in organic and hybrid solar cells. Energy Environ. Sci. 5(8), 8045 (2012).

15. L.M. Pazos-Outon, M. Szumilo, R. Lamboll, J.M. Richter, M. Crespo-Quesada, M. Abdi-Jalebi, H.J. Beeson, M. Vrućinić, M. Alsari, H.J. Snaith, B. Ehrler, R.H. Friend, and F. Deschler: Photon recycling in lead iodide perovskite solar cells. Science 351(6280), 1430 (2016).

16. T.M. Brenner, D.A. Egger, L. Kronik, G. Hodes, and D. Cahen: Hybrid organic-inorganic perovskites: Low-cost semiconductors with intriguing charge-transport properties. Nat. Rev. Mater. 1(1), 15007 (2016).

17. B.R. Sutherland and E.H. Sargent: Perovskite photonic sources. Nat. Photonics 10(5), 295 (2016).
18. H. Zhu, K. Miyata, Y. Fu, J. Wang, P.P. Joshi, D. Niesner, K.W. Williams, S. Jin, and X.Y. Zhu: Screening in crystalline liquids protects energetic carriers in hybrid perovskites. Science 353(6306), 1409 (2016).

19. W. Zhang, G.E. Eperon, and H.J. Snaith: Metal halide perovskites for energy applications. Nat. Energy 1(6), 16048 (2016).

20. C.C. Stoumpos and M.G. Kanatzidis: Halide perovskites: Poor Man's high-performance semiconductors. Adv. Mater. 28(28), 5778 (2016).

21. C.C. Stoumpos and M.G. Kanatzidis: The renaissance of halide perovskites and their evolution as emerging semiconductors. Acc. Chem. Res. 48(10), 2791 (2015).

22. Y. Deng, E. Peng, Y. Shao, Z. Xiao, Q. Dong, and J. Huang: Scalable fabrication of efficient organolead trihalide perovskite solar cells with doctor-bladed active layers. Energy Environ. Sci. 8(5), 1544 (2015).

23. A.T. Barrows, A.J. Pearson, C.K. Kwak, A.D.F. Dunbar, A.R. Buckley, and D.G. Lidzey: Efficient planar heterojunction mixed-halide perovskite solar cells deposited via spray-deposition. Energy Environ. Sci. 7(9), 2944 (2014).

24. K. Hwang, Y-S. Jung, Y-J. Heo, F.H. Scholes, S.E. Watkins, J. Subbiah, D.J. Jones, D-Y. Kim, and D. Vak: Toward large scale roll-to-roll production of fully printed perovskite solar cells. Adv. Mater. 27(7), 1241 (2015).

25. T.M. Schmidt, T.T. Larsen-Olsen, J.E. Carlé, D. Angmo, and F.C. Krebs: Upscaling of perovskite solar cells: Fully ambient roll processing of flexible perovskite solar cells with printed back electrodes. Adv. Energy Mater. 5(15), 1500569 (2015).

26. G. Li, Z-K. Tan, D. Di, M.L. Lai, L. Jiang, J.H-W. Lim, R.H. Friend, and N.C. Greenham: Efficient light-emitting diodes based on nanocrystalline perovskite in a dielectric polymer matrix. Nano Lett. 15(4), 2640 (2015).

27. Y-H. Kim, H. Cho, J.H. Heo, T-S. Kim, N. Myoung, C-L. Lee, S.H. Im, and T-W. Lee: Multicolored organic/inorganic hybrid perovskite light-emitting diodes. Adv. Mater. 27(7), 1248 (2015).

28. H. Cho, S.H. Jeong, M.H. Park, Y.H. Kim, C. Wolf, C.L. Lee, J.H. Heo, A. Sadhanala, N. Myoung, S. Yoo, S.H. Im, R.H. Friend, and T.W. Lee: Overcoming the electroluminescence efficiency limitations of perovskite light-emitting diodes. Science 350(6265), 1222 (2015).

29. N. Wang, L. Cheng, R. Ge, S. Zhang, Y. Miao, W. Zou, C. Yi, Y. Sun, Y. Cao, R. Yang, Y. Wei, Q. Guo, Y. Ke, M. Yu, Y. Jin, Y. Liu, Q. Ding, D. Di, L. Yang, G. Xing, H. Tian, C. Jin, F. Gao, R.H. Friend, J. Wang, and W. Huang: Perovskite lightemitting diodes based on solution-processed self-organized multiple quantum wells. Nat. Photonics 10(11), 699 (2016)

30. A Web of Science search on the 29th November 2016 for "Topic $=$ Perovskite solar cell' and 'Document type $=$ 'Review"' returned 163 results, including 93 for the 2016 publication year.

31. M.M. Lee, J. Teuscher, T. Miyasaka, T.N. Murakami, and H.J. Snaith: Efficient hybrid solar cells based on mesosuperstructured organometal halide perovskites. Science 338(6107), 643 (2012).

32. J. Burschka, N. Pellet, S-J. Moon, R. Humphry-Baker, P. Gao, M.K. Nazeeruddin, and M. Grätzel: Sequential deposition as a route to high-performance perovskite-sensitized solar cells. Nature 499(7458), 316 (2013).

33. A. Kojima, K. Teshima, Y. Shirai, and T. Miyasaka: Organometal halide perovskites as visible-light sensitizers for photovoltaic cells. J. Am. Chem. Soc. 131(17), 6050 (2009).

34. W. Travis, E.N.K. Glover, H. Bronstein, D.O. Scanlon, and R.G. Palgrave: On the application of the tolerance factor to inorganic and hybrid halide perovskites: A revised system. Chem. Sci. 7(7), 4548 (2016). 
35. M. Saliba, T. Matsui, K. Domanski, J.Y. Seo, A. Ummadisingu, S.M. Zakeeruddin, J.P. Correa-Baena, W.R. Tress, A. Abate, A. Hagfeldt, and M. Gratzel: Incorporation of rubidium cations into perovskite solar cells improves photovoltaic performance. Science 354(6309), 206 (2016).

36. G.E. Eperon, T. Leijtens, K.A. Bush, R. Prasanna, T. Green, J.T.W. Wang, D.P. McMeekin, G. Volonakis, R.L. Milot, R. May, A. Palmstrom, D.J. Slotcavage, R.A. Belisle, J.B. Patel, E.S. Parrott, R.J. Sutton, W. Ma, F. Moghadam, B. Conings, A. Babayigit, H.G. Boyen, S. Bent, F. Giustino, L.M. Herz, M.B. Johnston, M.D. McGehee, and H.J. Snaith: Perovskite-perovskite tandem photovoltaics with optimized band gaps. Science 354(6314), 861 (2016).

37. M. Liu, M.B. Johnston, and H.J. Snaith: Efficient planar heterojunction perovskite solar cells by vapour deposition. Nature 501(7467), 395 (2013).

38. P. Pistor, J. Borchert, W. Fränzel, R. Csuk, and R. Scheer: Monitoring the phase formation of coevaporated lead halide perovskite thin films by in situ X-ray diffraction. J. Phys. Chem. Lett. 5(19), 3308 (2014).

39. C.C. Stoumpos, C.D. Malliakas, and M.G. Kanatzidis: Semiconducting tin and lead iodide perovskites with organic cations: Phase transitions, high mobilities, and near-infrared photoluminescent properties. Inorg. Chem. 52(15), 9019 (2013).

40. T. Baikie, Y. Fang, J.M. Kadro, M. Schreyer, F. Wei, S.G. Mhaisalkar, M. Graetzel, and T.J. White: Synthesis and crystal chemistry of the hybrid perovskite $\left(\mathrm{CH}_{3} \mathrm{NH}_{3}\right) \mathrm{PbI}_{3}$ for solid-state sensitised solar cell applications. J. Mater. Chem. A 1(18), 5628 (2013).

41. Y. Kawamura, H. Mashiyama, and K. Hasebe: Structural study on cubic-tetragonal transition of $\mathrm{CH}_{3} \mathrm{NH}_{3} \mathrm{PbI}_{3}$. J. Phys. Soc. Jpn. 71(7), 1694 (2002).

42. Q. Wang, M. Lyu, M. Zhang, J-H. Yun, H. Chen, and L. Wang: Transition from the tetragonal to cubic phase of organohalide perovskite: The role of chlorine in crystal formation of $\mathrm{CH}_{3} \mathrm{NH}_{3} \mathrm{PbI}_{3}$ on $\mathrm{TiO}_{2}$ substrates. J. Phys. Chem. Lett. 6(21), 4379 (2015).

43. J.H. Noh, S.H. Im, J.H. Heo, T.N. Mandal, and S.I. Seok: Chemical management for colorful, efficient, and stable inorganic-organic hybrid nanostructured solar cells. Nano Lett. 13(4), 1764 (2013).

44. Q. Chen, H. Zhou, Y. Fang, A.Z. Stieg, T-B. Song, H-H. Wang, X. Xu, Y. Liu, S. Lu, J. You, P. Sun, J. McKay, M.S. Goorsky, and Y. Yang: The optoelectronic role of chlorine in $\mathrm{CH}_{3} \mathrm{NH}_{3} \mathrm{PbI}_{3}$ (Cl)-based perovskite solar cells. Nat. Commun. 6, 7269 (2015).

45. S.D. Stranks, G.E. Eperon, G. Grancini, C. Menelaou, M.J.P. Alcocer, T. Leijtens, L.M. Herz, A. Petrozza, and H.J. Snaith: Electron-hole diffusion lengths exceeding $1 \mathrm{mi}-$ crometer in an organometal trihalide perovskite absorber. Science 342(6156), 341 (2013).

46. S. Colella, E. Mosconi, G. Pellegrino, A. Alberti, V.L.P. Guerra, S. Masi, A. Listorti, A. Rizzo, G.G. Condorelli, F. De Angelis, and G. Gigli: Elusive presence of chloride in mixed halide perovskite solar cells. J. Phys. Chem. Lett. 5(20), 3532 (2014).

47. G. Grancini, S. Marras, M. Prato, C. Giannini, C. Quarti, F. De Angelis, M. De Bastiani, G.E. Eperon, H.J. Snaith, L. Manna, and A. Petrozza: The impact of the crystallization processes on the structural and optical properties of hybrid perovskite films for photovoltaics. J. Phys. Chem. Lett. 5(21), 3836 (2014).

48. H. Yu, F. Wang, F. Xie, W. Li, J. Chen, and N. Zhao: The role of chlorine in the formation process of " $\mathrm{CH}_{3} \mathrm{NH}_{3} \mathrm{PbI}_{3-x} \mathrm{Cl}_{x}$ " perovskite. Adv. Funct. Mater. 24(45), 7102-7108 (2014).

49. A. Dualeh, N. Tétreault, T. Moehl, P. Gao, M.K. Nazeeruddin, and M. Grätzel: Effect of annealing temperature on film morphology of organic-inorganic hybrid pervoskite solid-state solar cells. Adv. Funct. Mater. 24(21), 3250 (2014).
50. G.E. Eperon, S.N. Habisreutinger, T. Leijtens, B.J. Bruijnaers, J.J. van Franeker, D.W. deQuilettes, S. Pathak, R.J. Sutton, G. Grancini, D.S. Ginger, R.A.J. Janssen, A. Petrozza, and H.J. Snaith: The importance of moisture in hybrid lead halide perovskite thin film fabrication. ACS Nano 9(9), 9380 (2015).

51. A.M.A. Leguy, Y. Hu, M. Campoy-Quiles, M.I. Alonso, O.J. Weber, P. Azarhoosh, M. van Schilfgaarde, M.T. Weller, T. Bein, J. Nelson, P. Docampo, and P.R.F. Barnes: Reversible hydration of $\mathrm{CH}_{3} \mathrm{NH}_{3} \mathrm{PbI}_{3}$ in films, single crystals, and solar cells. Chem. Mater. 27(9), 3397 (2015).

52. E.L. Unger, A.R. Bowring, C.J. Tassone, V.L. Pool, A. Gold-Parker, R. Cheacharoen, K.H. Stone, E.T. Hoke, M.F. Toney, and M.D. McGehee: Chloride in lead chloridederived organo-metal halides for perovskite-absorber solar cells. Chem. Mater. 26(24), 7158 (2014).

53. A.T. Barrows, S. Lilliu, A.J. Pearson, D. Babonneau, A.D.F. Dunbar, and D.G. Lidzey: Monitoring the formation of a $\mathrm{CH}_{3} \mathrm{NH}_{3} \mathrm{PbI}_{3-x} \mathrm{Cl}_{x}$ perovskite during thermal annealing using X-ray scattering. Adv. Funct. Mater. 26(27), 4934 (2016).

54. D.T. Moore, H. Sai, K.W. Tan, D-M. Smilgies, W. Zhang, H.J. Snaith, U. Wiesner, and L.A. Estroff: Crystallization kinetics of organic-inorganic trihalide perovskites and the role of the lead anion in crystal growth. J. Am. Chem. Soc. 137(6), 2350 (2015).

55. K.W. Tan, D.T. Moore, M. Saliba, H. Sai, L.A. Estroff, T. Hanrath, H.J. Snaith, and U. Wiesner: Thermally induced structural evolution and performance of mesoporous block copolymer-directed alumina perovskite solar cells. ACS Nano 8(5), 4730 (2014).

56. L.H. Rossander, T.T. Larsen-Olsen, H.F. Dam, T.M. Schmidt, M. Corazza, K. Norrman, I. Rajkovic, J.W. Andreasen, and F.C. Krebs: In situ X-ray scattering of perovskite solar cell active layers roll-to-roll coated on flexible substrates. CrystEngComm 18(27), 5083 (2016).

57. D.P. Nenon, J.A. Christians, L.M. Wheeler, J.L. Blackburn, E.M. Sanehira, B. Dou, M.L. Olsen, K. Zhu, J.J. Berry, and J.M. Luther: Structural and chemical evolution of methylammonium lead halide perovskites during thermal processing from solution. Energy Environ. Sci. 9(6), 2072 (2016).

58. C-Y. Chang, Y-C. Huang, C-S. Tsao, and W-F. Su: Formation mechanism and control of perovskite films from solution to crystalline phase studied by in situ synchrotron scattering. ACS Appl. Mater. Interfaces 8(40), 26712 (2016).

59. S. Lilliu, J. Griffin, A.T. Barrows, M. Alsari, B. Curzadd, T.G. Dane, O. Bikondoa, J.E. Macdonald, and D.G. Lidzey: Grain rotation and lattice deformation during perovskite spray coating and annealing probed in situ by GI-WAXS. CrystEngComm 18(29), 5448 (2016).

60. S.T. Williams, F. Zuo, C-C. Chueh, C-Y. Liao, P-W. Liang, and A.K.Y. Jen: Role of chloride in the morphological evolution of organo-lead halide perovskite thin films. ACS Nano 8(10), 10640 (2014).

61. G.E. Eperon, V.M. Burlakov, P. Docampo, A. Goriely, and H.J. Snaith: Morphological control for high performance, solution-processed planar heterojunction perovskite solar cells. Adv. Funct. Mater. 24(1), 151 (2014).

62. R. Kang, J-E. Kim, J-S. Yeo, S. Lee, Y-J. Jeon, and D-Y. Kim: Optimized organometal halide perovskite planar hybrid solar cells via control of solvent evaporation rate. J. Phys. Chem. C 118(46), 26513 (2014).

63. M-F. Xu, H. Zhang, S. Zhang, H.L. Zhu, H-M. Su, J. Liu, K.S. Wong, L-S. Liao, and W.C.H. Choy: A low temperature gradual annealing scheme for achieving high performance perovskite solar cells with no hysteresis. J. Mater. Chem. A 3(27), 14424 (2015). 
64. D.H. Cao, C.C. Stoumpos, C.D. Malliakas, M.J. Katz, O.K. Farha, J.T. Hupp, and M.G. Kanatzidis: Remnant $\mathrm{PbI}_{2}$, an unforeseen necessity in high-efficiency hybrid perovskitebased solar cells? APL Mater. 2(9), 091101 (2014).

65. T.J. Jacobsson, J-P. Correa-Baena, E. Halvani Anaraki, B. Philippe, S.D. Stranks, M.E.F. Bouduban, W. Tress, K. Schenk, J. Teuscher, J-E. Moser, H. Rensmo, and A. Hagfeldt: Unreacted $\mathrm{PbI}_{2}$ as a double-edged sword for enhancing the performance of perovskite solar cells. J. Am. Chem. Soc. 138(32), 10331 (2016).

66. F. Liu, Q. Dong, M.K. Wong, A.B. Djurišić, A. Ng, Z. Ren, Q. Shen, C. Surya, W.K. Chan, J. Wang, A.M.C. Ng, C. Liao, H. Li, K. Shih, C. Wei, H. Su, and J. Dai: Is excess $\mathrm{PbI}_{2}$ beneficial for perovskite solar cell performance? Adv. Energy Mater. 6(7), 1502206 (2016)

67. Q. Chen, H. Zhou, Z. Hong, S. Luo, H-S. Duan, H-H. Wang, Y. Liu, G. Li, and Y. Yang: Planar heterojunction perovskite solar cells via vapor-assisted solution process. J. Am. Chem. Soc. 136(2), 622 (2014).

68. Z. Zhou, Z. Wang, Y. Zhou, S. Pang, D. Wang, H. Xu, Z. Liu, N.P. Padture, and G. Cui: Methylamine-gas-induced defecthealing behavior of $\mathrm{CH}_{3} \mathrm{NH}_{3} \mathrm{PbI}_{3}$ thin films for perovskite solar cells. Angew. Chem., Int. Ed. 54(33), 9705 (2015).

69. Z. Xiao, Q. Dong, C. Bi, Y. Shao, Y. Yuan, and J. Huang: Solvent annealing of perovskite-induced crystal growth for photovoltaic-device efficiency enhancement. Adv. Mater. 26(37), 6503 (2014)

70. H. Yu, X. Liu, Y. Xia, Q. Dong, K. Zhang, Z. Wang, Y. Zhou, B. Song, and Y. Li: Room-temperature mixed-solvent-vapor annealing for high performance perovskite solar cells. J. Mater. Chem. A 4(1), 321 (2016).

71. J. You, Y. Yang, Z. Hong, T-B. Song, L. Meng, Y. Liu, C. Jiang, H. Zhou, W-H. Chang, G. Li, and Y. Yang: Moisture assisted perovskite film growth for high performance solar cells. Appl. Phys. Lett. 105(18), 183902 (2014).

72. J.L. Urai: Water assisted dynamic recrystallization and weakening in polycrystalline bischofite. Tectonophysics 96(1-2), 125 (1983)

73. M.L. Petrus, Y. Hu, D. Moia, P. Calado, A.M.A. Leguy, P.R.F. Barnes, and P. Docampo: The influence of water vapor on the stability and processing of hybrid perovskite solar cells made from non-stoichiometric precursor mixtures. Chemsuschem 9(18), 2699 (2016).

74. W. Zhang, M. Saliba, D.T. Moore, S.K. Pathak, M.T. Hörantner, T. Stergiopoulos, S.D. Stranks, G.E. Eperon, J.A. AlexanderWebber, A. Abate, A. Sadhanala, S. Yao, Y. Chen, R.H. Friend, L.A. Estroff, U. Wiesner, and H.J. Snaith: Ultrasmooth organicinorganic perovskite thin-film formation and crystallization for efficient planar heterojunction solar cells. Nat. Commun. 6, 6142 (2015).

75. N.J. Jeon, J.H. Noh, Y.C. Kim, W.S. Yang, S. Ryu, and S.I. Seok: Solvent engineering for high-performance inorganicorganic hybrid perovskite solar cells. Nat. Mater. 13(9), 897 (2014).

76. N.K. Noel, S.N. Habisreutinger, B. Wenger, M.T. Klug, M.T. Hörantner, M.B. Johnston, R.J. Nicholas, D.T. Moore, and H.J. Snaith: A low viscosity, low boiling point, clean solvent system for the rapid crystallisation of highly specular perovskite films. Energy Environ. Sci. 10, 145-152 (2017).

77. P-W. Liang, C-Y. Liao, C-C. Chueh, F. Zuo, S.T. Williams, X-K. Xin, J. Lin, and A.K.Y. Jen: Additive enhanced crystallization of solution-processed perovskite for highly efficient planar-heterojunction solar cells. Adv. Mater. 26(22), 3748 (2014).

78. C-C. Chueh, C-Y. Liao, F. Zuo, S.T. Williams, P-W. Liang, and A.K.Y. Jen: The roles of alkyl halide additives in enhancing perovskite solar cell performance. J. Mater. Chem. A 3(17), 9058 (2015).

79. J.S. Manser, B. Reid, and P.V. Kamat: Evolution of organicinorganic lead halide perovskite from solid-state iodoplumbate complexes. J. Phys. Chem. C 119(30), 17065 (2015).

80. S.J. Yoon, K.G. Stamplecoskie, and P.V. Kamat: How lead halide complex chemistry dictates the composition of mixed halide perovskites. J. Phys. Chem. Lett. 7(7), 1368 (2016).

81. W. Zhang, S. Pathak, N. Sakai, T. Stergiopoulos, P.K. Nayak, N.K. Noel, A.A. Haghighirad, V.M. Burlakov, D.W. deQuilettes, A. Sadhanala, W. Li, L. Wang, D.S. Ginger, R.H. Friend, and H.J. Snaith: Enhanced optoelectronic quality of perovskite thin films with hypophosphorous acid for planar heterojunction solar cells. Nat. Commun. 6, 10030 (2015).

82. J.W. Jung, S.T. Williams, and A.K.Y. Jen: Low-temperature processed high-performance flexible perovskite solar cells via rationally optimized solvent washing treatments. RSC $A d v$. 4(108), 62971 (2014).

83. N. Ahn, D-Y. Son, I-H. Jang, S.M. Kang, M. Choi, and N-G. Park: Highly reproducible perovskite solar cells with average efficiency of $18.3 \%$ and best efficiency of $19.7 \%$ fabricated via Lewis base adduct of lead(II) iodide. J. Am. Chem. Soc. 137(27), 8696 (2015).

84. T. Miyadera, Y. Shibata, T. Koganezawa, T.N. Murakami, T. Sugita, N. Tanigaki, and M. Chikamatsu: Crystallization dynamics of organolead halide perovskite by real-time X-ray diffraction. Nano Lett. 15(8), 5630 (2015).

85. B. Yang, J. Keum, O.S. Ovchinnikova, A. Belianinov, S. Chen, M-H. Du, I.N. Ivanov, C.M. Rouleau, D.B. Geohegan, and K. Xiao: Deciphering halogen competition in organometallic halide perovskite growth. J. Am. Chem. Soc. 138(15), 5028 (2016).

86. G.E. Eperon, S.D. Stranks, C. Menelaou, M.B. Johnston, L.M. Herz, and H.J. Snaith: Formamidinium lead trihalide: A broadly tunable perovskite for efficient planar heterojunction solar cells. Energy Environ. Sci. 7(3), 982 (2014).

87. T.M. Koh, K. Fu, Y. Fang, S. Chen, T.C. Sum, N. Mathews, S.G. Mhaisalkar, P.P. Boix, and T. Baikie: Formamidiniumcontaining metal-halide: An alternative material for near-IR absorption perovskite solar cells. J. Phys. Chem. C 118(30), 16458 (2014).

88. J.A. Aguiar, S. Wozny, T.G. Holesinger, T. Aoki, M.K. Patel, M. Yang, J.J. Berry, M. Al-Jassim, W. Zhou, and K. Zhu: In situ investigation of the formation and metastability of formamidinium lead tri-iodide perovskite solar cells. Energy Environ. Sci. 9(7), 2372 (2016).

89. M.R. Leyden, M.V. Lee, S.R. Raga, and Y. Qi: Large formamidinium lead trihalide perovskite solar cells using chemical vapor deposition with high reproducibility and tunable chlorine concentrations. J. Mater. Chem. A 3(31), 16097 (2015).

90. J. Yang, B.D. Siempelkamp, D. Liu, and T.L. Kelly: Investigation of $\mathrm{CH}_{3} \mathrm{NH}_{3} \mathrm{PbI}_{3}$ degradation rates and mechanisms in controlled humidity environments using in situ techniques. ACS Nano 9(2), 1955 (2015).

91. N. Aristidou, I. Sanchez-Molina, T. Chotchuangchutchaval, M. Brown, L. Martinez, T. Rath, and S.A. Haque: The role of oxygen in the degradation of methylammonium lead trihalide perovskite photoactive layers. Angew. Chem., Int. Ed. 54(28), 8208 (2015).

92. D. Bryant, N. Aristidou, S. Pont, I. Sanchez-Molina, T. Chotchunangatchaval, S. Wheeler, J.R. Durrant, and S.A. Haque: Light and oxygen induced degradation limits the operational stability of methylammonium lead triiodide perovskite solar cells. Energy Environ. Sci. 9(5), 1655 (2016).

93. A.J. Pearson, G.E. Eperon, P.E. Hopkinson, S.N. Habisreutinger, J.T-W. Wang, H.J. Snaith, and N.C. Greenham: Oxygen 
degradation in mesoporous $\mathrm{Al}_{2} \mathrm{O}_{3} / \mathrm{CH}_{3} \mathrm{NH}_{3} \mathrm{PbI}_{3-x} \mathrm{Cl}_{x}$ perovskite solar cells: Kinetics and mechanisms. Adv. Energy Mater. 6(13), 1600014 (2016).

94. Y. Huang, E.J. Kramer, A.J. Heeger, and G.C. Bazan: Bulk heterojunction solar cells: Morphology and performance relationships. Chem. Rev. 114(14), 7006 (2014).

95. L. Lu, T. Zheng, Q. Wu, A.M. Schneider, D. Zhao, and L. Yu: Recent advances in bulk heterojunction polymer solar cells. Chem. Rev. 115(23), 12666 (2015).

96. M.A. Brady, G.M. Su, and M.L. Chabinyc: Recent progress in the morphology of bulk heterojunction photovoltaics. Soft Matter 7(23), 11065 (2011).

97. C.J. Bardeen: The structure and dynamics of molecular excitons. Annu. Rev. Phys. Chem. 65(1), 127 (2014).

98. A.A. Bakulin, A. Rao, V.G. Pavelyev, P.H.M. van Loosdrecht, M.S. Pshenichnikov, D. Niedzialek, J. Cornil, D. Beljonne, and R.H. Friend: The role of driving energy and delocalized states for charge separation in organic semiconductors. Science 335(6074), 1340 (2012).

99. S. Gelinas, A. Rao, A. Kumar, S.L. Smith, A.W. Chin, J. Clark, T.S. van der Poll, G.C. Bazan, and R.H. Friend: Ultrafast longrange charge separation in organic semiconductor photovoltaic diodes. Science 343(6170), 512 (2013).

100. F.C. Jamieson, E.B. Domingo, T. McCarthy-Ward, M. Heeney, N. Stingelin, and J.R. Durrant: Fullerene crystallisation as a key driver of charge separation in polymer/fullerene bulk heterojunction solar cells. Chem. Sci. 3(2), 485 (2012).

101. R.H. Friend, M. Phillips, A. Rao, M.W.B. Wilson, Z. Li, and C.R. McNeill: Excitons and charges at organic semiconductor heterojunctions. Faraday Discuss. 155, 339 (2012).

102. T.M. Clarke and J.R. Durrant: Charge photogeneration in organic solar cells. Chem. Rev. 110(11), 6736 (2010).

103. J.J.M. Halls, K. Pichler, R.H. Friend, S.C. Moratti, and A.B. Holmes: Exciton diffusion and dissociation in a poly ( $p$-phenylenevinylene)/ $\mathrm{C}_{60}$ heterojunction photovoltaic cell. Appl. Phys. Lett. 68(22), 3120 (1996).

104. P.E. Shaw, A. Ruseckas, and I.D.W. Samuel: Exciton diffusion measurements in poly(3-hexylthiophene). Adv. Mater. 20(18), 3516 (2008).

105. M.T. Dang, L. Hirsch, and G. Wantz: P3HT:PCBM, best seller in polymer photovoltaic research. Adv. Mater. 23(31), 3597 (2011).

106. T. Wang, A.D.F. Dunbar, P.A. Staniec, A.J. Pearson, P.E. Hopkinson, J.E. MacDonald, S. Lilliu, C. Pizzey, N.J. Terrill, A.M. Donald, A.J. Ryan, R.A.L. Jones, and D.G. Lidzey: The development of nanoscale morphology in polymer:fullerene photovoltaic blends during solvent casting. Soft Matter 6(17), 4128 (2010).

107. B. Schmidt-Hansberg, M. Sanyal, M.F.G. Klein, M. Pfaff, N. Schnabel, S. Jaiser, A. Vorobiev, E. Müller, A. Colsmann, P. Scharfer, D. Gerthsen, U. Lemmer, E. Barrena, and W. Schabel: Moving through the phase diagram: Morphology formation in solution cast polymer-fullerene blend films for organic solar cells. ACS Nano 5(11), 8579 (2011).

108. A.J. Pearson, T. Wang, A.D.F. Dunbar, H. Yi, D.C. Watters, D.M. Coles, P.A. Staniec, A. Iraqi, R.A.L. Jones, and D.G. Lidzey: Morphology development in amorphous polymer: fullerene photovoltaic blend films during solution casting. $A d v$. Funct. Mater. 24(5), 659 (2014).

109. F. Liu, Y. Gu, C. Wang, W. Zhao, D. Chen, A.L. Briseno, and T.P. Russell: Efficient polymer solar cells based on a low band gap semi-crystalline DPP polymer-PCBM blends. Adv. Mater. 24(29), 3947 (2012).

110. F. Liu, S. Ferdous, E. Schaible, A. Hexemer, M. Church, X. Ding, C. Wang, and T.P. Russell: Fast printing and in situ morphology observation of organic photovoltaics using slot-die coating. Adv. Mater. 27(5), 886 (2015).

111. J.J. van Franeker, M. Turbiez, W. Li, M.M. Wienk, and R.A.J. Janssen: A real-time study of the benefits of co-solvents in polymer solar cell processing. Nat. Commun. 6, 6229 (2015).

112. H-C. Liao, C-C. Ho, C-Y. Chang, M-H. Jao, S.B. Darling, and W-F. Su: Additives for morphology control in high-efficiency organic solar cells. Mater. Today 16(9), 326 (2013).

113. J.K. Lee, W.L. Ma, C.J. Brabec, J. Yuen, J.S. Moon, J.Y. Kim, K. Lee, G.C. Bazan, and A.J. Heeger: Processing additives for improved efficiency from bulk heterojunction solar cells. $J$. Am. Chem. Soc. 130(11), 3619 (2008).

114. F. Liu, W. Zhao, J.R. Tumbleston, C. Wang, Y. Gu, D. Wang, A.L. Briseno, H. Ade, and T.P. Russell: Understanding the morphology of PTB7:PCBM blends in organic photovoltaics. Adv. Energy Mater. 4(5), 1301377 (2014).

115. B.J. Tremolet de Villers, K.A. O’Hara, D.P. Ostrowski, P.H. Biddle, S.E. Shaheen, M.L. Chabinyc, D.C. Olson, and N. Kopidakis: Removal of residual diiodooctane improves photostability of high-performance organic solar cell polymers. Chem. Mater. 28(3), 876 (2016).

116. L.J. Richter, D.M. DeLongchamp, F.A. Bokel, S. Engmann, K.W. Chou, A. Amassian, E. Schaible, and A. Hexemer: In situ morphology studies of the mechanism for solution additive effects on the formation of bulk heterojunction films. $A d v$. Energy Mater. 5(3), 1400975 (2015).

117. A.J. Pearson, T. Wang, R.A.L. Jones, D.G. Lidzey, P.A. Staniec, P.E. Hopkinson, and A.M. Donald: Rationalizing phase transitions with thermal annealing temperatures for P3HT:PCBM organic photovoltaic devices. Macromolecules 45(3), 1499 (2012).

118. N.D. Treat, M.A. Brady, G. Smith, M.F. Toney, E.J. Kramer, C.J. Hawker, and M.L. Chabinyc: Interdiffusion of PCBM and P3HT reveals miscibility in a photovoltaically active blend. $A d v$. Energy Mater. 1(1), 82 (2011).

119. K.W. Chou, B. Yan, R. Li, E.Q. Li, K. Zhao, D.H. Anjum, S. Alvarez, R. Gassaway, A. Biocca, S.T. Thoroddsen, A. Hexemer, and A. Amassian: Spin-cast bulk heterojunction solar cells: A dynamical investigation. Adv. Mater. 25(13), 1923 (2013).

120. L.A. Perez, K.W. Chou, J.A. Love, T.S. van der Poll, D-M. Smilgies, T-Q. Nguyen, E.J. Kramer, A. Amassian, and G.C. Bazan: Solvent additive effects on small molecule crystallization in bulk heterojunction solar cells probed during spin casting. Adv. Mater. 25(44), 6380 (2013).

121. S. Engmann, F.A. Bokel, A.A. Herzing, H.W. Ro, C. Girotto, B. Caputo, C.V. Hoven, E. Schaible, A. Hexemer, D.M. DeLongchamp, and L.J. Richter: Real-time X-ray scattering studies of film evolution in high performing small-moleculefullerene organic solar cells. J. Mater. Chem. A 3(16), 8764 (2015).

122. Y. Liu, J. Zhao, Z. Li, C. Mu, W. Ma, H. Hu, K. Jiang, H. Lin, $\mathrm{H}$. Ade, and H. Yan: Aggregation and morphology control enables multiple cases of high-efficiency polymer solar cells. Nat. Commun. 5, 5293 (2014).

123. H.W. Ro, J.M. Downing, S. Engmann, A.A. Herzing, D.M. DeLongchamp, L.J. Richter, S. Mukherjee, H. Ade, M. Abdelsamie, L.K. Jagadamma, A. Amassian, Y. Liu, and H. Yan: Morphology changes upon scaling a high-efficiency, solution-processed solar cell. Energy Environ. Sci. 9(9), 2835 (2016).

124. K. Zhao, H. Hu, E. Spada, L.K. Jagadamma, B. Yan, M. Abdelsamie, Y. Yang, L. Yu, R. Munir, R. Li, G.O.N. Ndjawa, and A. Amassian: Highly efficient polymer solar cells with printed photoactive layer: Rational process 
transfer from spin-coating. J. Mater. Chem. A 4(41), 16036 (2016).

125. B.A. Collins, E. Gann, L. Guignard, X. He, C.R. McNeill, and H. Ade: Molecular miscibility of polymer-fullerene blends. J. Phys. Chem. Lett. 1(21), 3160 (2010).

126. T. Wang, A.J. Pearson, D.G. Lidzey, and R.A.L. Jones: Evolution of structure, optoelectronic properties, and device performance of polythiophene: Fullerene solar cells during thermal annealing. Adv. Funct. Mater. 21(8), 1383 (2011).

127. A. Sharenko, M. Kuik, M.F. Toney, and T-Q. Nguyen: Crystallization-induced phase separation in solution-processed small molecule bulk heterojunction organic solar cells. Adv. Funct. Mater. 24(23), 3543 (2014).

128. S. Engmann, H.W. Ro, A. Herzing, C.R. Snyder, L.J. Richter, P.B. Geraghty, and D.J. Jones: Film morphology evolution during solvent vapor annealing of highly efficient small molecule donor/acceptor blends. J. Mater. Chem. A 4(40), 15511 (2016).

129. E. Verploegen, C.E. Miller, K. Schmidt, Z. Bao, and M.F. Toney: Manipulating the morphology of P3HT-PCBM bulk heterojunction blends with solvent vapor annealing. Chem. Mater. 24(20), 3923 (2012).

130. C.J. Schaffer, C.M. Palumbiny, M.A. Niedermeier, C. Jendrzejewski, G. Santoro, S.V. Roth, and P. Müller-Buschbaum: A direct evidence of morphological degradation on a nanometer scale in polymer solar cells. Adv. Mater. 25(46), 6760 (2013).

131. W. Wang, C.J. Schaffer, L. Song, V. Körstgens, S. Pröller, E.D. Indari, T. Wang, A. Abdelsamie, S. Bernstorff, and P. Müller-Buschbaum: In operando morphology investigation of inverted bulk heterojunction organic solar cells by GISAXS J. Mater. Chem. A 3(16), 8324 (2015).

132. P.E. Hopkinson, P.A. Staniec, A.J. Pearson, A.D.F. Dunbar, T. Wang, A.J. Ryan, R.A.L. Jones, D.G. Lidzey, and A.M. Donald: A phase diagram of the P3HT:PCBM organic photovoltaic system: Implications for device processing and performance. Macromolecules 44(8), 2908 (2011).

133. Z. Li, H.C. Wong, Z. Huang, H. Zhong, C.H. Tan, W.C. Tsoi, J.S. Kim, J.R. Durrant, and J.T. Cabral: Performance enhancement of fullerene-based solar cells by light processing. Nat. Commun. 4, 2227 (2013).

134. S.Y. Leblebici, L. Leppert, Y. Li, S.E. Reyes-Lillo, S. Wickenburg, E. Wong, J. Lee, M. Melli, D. Ziegler, D.K. Angell, D.F. Ogletree, P.D. Ashby, F.M. Toma, J.B. Neaton, I.D. Sharp, and A. Weber-Bargioni: Facet-dependent photovoltaic efficiency variations in single grains of hybrid halide perovskite. Nat. Energy 1(8), 16093 (2016).

135. S. Lilliu, T.G. Dane, M. Alsari, J. Griffin, A.T. Barrows, M.S. Dahlem, R.H. Friend, D.G. Lidzey, and J.E. Macdonald: Mapping morphological and structural properties of lead halide perovskites by scanning nanofocus XRD. Adv. Funct. Mater. 26(45), 8221 (2016)

136. X. Li, D. Bi, C. Yi, J.D. Decoppet, J. Luo, S.M. Zakeeruddin, A. Hagfeldt, and M. Gratzel: A vacuum flash-assisted solution process for high-efficiency large-area perovskite solar cells. Science 353(6294), 58 (2016).

137. W. Zhao, D. Qian, S. Zhang, S. Li, O. Inganäs, F. Gao, and J. Hou: Fullerene-free polymer solar cells with over $11 \%$ efficiency and excellent thermal stability. Adv. Mater. 28(23), 4734 (2016). 